Research Article

\title{
Reservoir Landslide Physical Modelling under Ice-Snow Melting and Reservoir Water Combined Action
}

\author{
Tongqiang Xiong, ${ }^{1,2}$ Jianlin Li $\mathbb{D},{ }^{1}$ Lehua Wang, ${ }^{1}$ Huafeng Deng, ${ }^{1}$ and Xiaoliang Xu ${ }^{1}$ \\ ${ }^{1}$ Key Laboratory of Geological Hazards on Three Gorges Reservoir Area, Ministry of Education, China Three Gorges University, \\ Yichang 443002, China \\ ${ }^{2}$ College of Hydraulic \& Environmental Engineering, China Three Gorges University, Yichang 443002, China
}

Correspondence should be addressed to Jianlin Li; ljl@ctgu.edu.cn

Received 17 September 2020; Revised 8 October 2020; Accepted 29 October 2020; Published 7 December 2020

Academic Editor: Xingzhou Chen

Copyright (C) 2020 Tongqiang Xiong et al. This is an open access article distributed under the Creative Commons Attribution License, which permits unrestricted use, distribution, and reproduction in any medium, provided the original work is properly cited.

\begin{abstract}
Extreme ice-snow melting in winter affects the infiltration process of snow water on the slope surface significantly and plays an important role in the deformation stability of landslide. Variation in pore water pressure is regarded as an essential factor of landslide instability induced by snow water. In order to figure out the internal relationship between the infiltration process of snow water and the failure mode of deformation and instability of the accumulation landslide, the response law and deformation and failure mode of pore water pressure and soil pressure of landslide accumulation under different ice-snow melting conditions are deeply studied based on the indoor large-scale landslide model test. We have studied the physical model test under the combined action of reservoir water and ice-snow melting. It reveals the seepage erosion deformation and failure mechanism. It undoubtedly provides references of great importance for the geological hazard governance of bank slope in the Three Gorges Reservoir Area.
\end{abstract}

\section{Introduction}

In early 2008, the rare ice-snow climate occurred and induced large geological disasters in southern China. The soil within $5 \mathrm{~cm}-10 \mathrm{~cm}$ underground can be frozen in short time and tends to form freezing-thawing cycles. The process of thawing ice is short and can form centralized surface runoffs. Frost-heaving force of surface frozen soil will not directly induce landslide and collapse; however, the repeated freezing-thawing of surface soil and the infiltration of melting ice and snow are the main factors of geological disasters.

Extreme ice-snow disasters are characterized by a large amount of ice and snow, deep snow, and a long duration of low temperature and freezing. After the extreme ice-snow disaster in the Three Gorges Reservoir Area of China, the ice-snow melting did not reach the level of rainstorm [1]. In the Three Gorges Reservoir Area of China, water reservoir landslides are affected by the reservoir water and hydrodynamic conditions, such as rainfall and reservoir water level variation, and they do have different degrees of impacts on the stability of these landslides [2-7]. The infiltration of ice-snow melting is one of the important factors that induce the slope instability in winter [8]. The slope instability caused by snow melting is a long-term lag accumulation effect [9]. In view of the research results obtained by stability analysis of the bank slope under the extreme ice-snow disaster weather [10], the extreme icesnow boundary conditions and the seepage characteristics of slope rock mass were adopted for reference. The stability analysis of the bank slope under the condition of ice-snow melting is conducted the seepage calculation and stability analysis of snow melting infiltration under different factors [11], using the saturated-unsaturated seepage finite element method [12], during which process the statistical data of snow thickness. The key to the numerical simulation of the slope instability is revealed theoretically the change process of the slope stress [13-15], characteristics and failure process 
of the infiltration, and the transient additional water load [16]. The distribution of the soil saturation factor in time and space is obtained by using GIS platform [17]. Through the numerical simulation of energy balance equation and water balance equation [18], a physical snow melting model based on the single point and double layer is established [19], and a theoretical model of snow ion infiltration is proposed simultaneously, which shows that the relationship between ion concentration and infiltration volume is nonlinear and positive covariance [20]. The snowmelt yield and confluence are simulated to improve the simulation accuracy; the water heat stress coupling numerical simulation of rock freezing and thawing cycle is studied [21].

The overturning stability coefficient of rock slope changes obviously due to the influence of extreme ice-snow disaster [22]. Snow water infiltrates along the fracture, and the water in the fracture freezes after freezing. The original equilibrium failure results in landslides and collapses [23]. If the effect is combined with reservoir water variation, the possibility and scale of landslides and collapses may be bigger. The reliability of slope under different working conditions is calculated and analyzed, respectively [24]. According to the field investigation, the main causes and factors of the soil slope's freeze-thaw instability are discussed [25-27]. Moreover, although many landslide model tests of combined effect of rainstorm and reservoir water have been carried out [28-34], large-scale three-dimensional physical model tests of the reservoir bank slope under the combined action of snow melting and reservoir water are in urgent need.

In 2000, Yigong landslide occurred in permafrost regions of China, the ice-snow melting causes landslides and debris flow, and the ice-snow melting has caused huge geological disasters of rock and soil. In comparison with extreme ice-snow in the Three Gorges Reservoir Area, the depth, thermal, and freeze-thaw processes are not the same, the rare ice-snow climate occurred in the Three Gorges Reservoir Area is rare, and the geological disaster caused by it has not been paid enough attention. In addition, there are great differences in topography, geological environment, climate environment, and so on. Therefore, under the condition of extreme snow and ice disaster in the middle and low latitudes of the Three Gorges Reservoir Area in China, the theoretical, experimental, and numerical studies on the types of geological disasters and their influencing mechanisms are basically blank.

\section{Methods and Materials}

2.1. Physical Model. The preliminary design scheme of the three-dimensional artificial landslide model test steel frame mainly includes the following two modes: the outer inclined support mode and the rotating staircase mode, both meet the test requirements. In consideration of the high requirements for longitudinal rigidity in the middle, through the $3 \mathrm{D}$ finite element calculation and research, the external inclined support mode covers a large area and needs high rigidity of the inclined support steel frame. After optimization and combination, the rotary stair type scheme is then formed and selected. The concrete-filled steel tube support is adopted, which greatly improves the longitudinal rigidity of the model steel frame. The internal dimension is $12 \mathrm{~m}$ long, $6 \mathrm{~m}$ high, and $6 \mathrm{~m}$ wide, adopting the open top steel structure form and water sealing material. The lateral deformation is required to be within $0.3 \%$, and its structure and system composition are shown in Figure 1.

2.2. Model Generalization. In this paper, the research object of the project is the area where the Outang landslide is located in Anping Town, Fengjie County, Chongqing, which is located on the right bank of the Three Gorges Reservoir $12 \mathrm{~km}$ upstream of Fengjie County. Landslides have been formed by multilevel and multistage sliding in the geological history, and the scale is huge. Since the impoundment of the Three Gorges project, the front edge of the Outang landslide has been submerged by the reservoir water, resulting in large deformation.

The overall form of the landslide is like an ancient bell with a spoon-shaped profile. The total area is about $1.78 \mathrm{~km}^{2}$, the total volume is about $9000 \times 104 \mathrm{~m}^{3}$, and the thickness of the sliding body in the front part is over $110 \mathrm{~m}$. The maximum longitudinal length of the landslide is about $1800 \mathrm{~m}$, the maximum width of the front edge along the river channel is about $1100 \mathrm{~m}$, and the width of the back edge is about $580 \mathrm{~m}$. The elevation of the front edge is about $95 \mathrm{~m}$, part of it is submerged below the water level of the reservoir, the elevation of the back edge is about $705 \mathrm{~m}$, and the relative height difference between the front edge and the back edge is about $610 \mathrm{~m}$. The surface of the earth is steep and gentle, showing a broken line, with an average slope of about $26^{\circ}$. The plan of the Outang landslide is shown in Figure 2.

The shallow sliding mass has a better permeability in the east and west of the Outang landslide. The deformation trend of groundwater and reservoir water is synchronous. The soaking softening effect of reservoir water on sliding belt is quite obvious. The anti-sliding force of the anti-slide section is significantly reduced. Because the cataclastic rock mass adjusts the stress, creep occurs along the potential bedding slip surface. The severe deformation areas in the east and west are mainly affected by precipitation (snow).

Based on the principle of reflecting the deformation, failure characteristics, and evolution process of the Outang landslide and according to the detailed investigation report of the Outang landslide in Fengjie County, the model test satisfied the requirements of geometric, material, kinematic, and dynamic similarities and simulated the anticipated loading conditions. The model test results can be used to predict the deformation and failure modes of the reservoir landslide. The boundary conditions and relevant information were determined from the field investigation and the topomap. The MATLAB software was used to extract the $3 \mathrm{D}$ coordinates and elevations. Moreover, the total station was used to set out the model construction. The model was established based on the observed one of landslide at the Three Gorges Reservoir Area. The scale ratio between the model and the prototype was $1: 175$. The landslide model section is shown in Figure 3. 


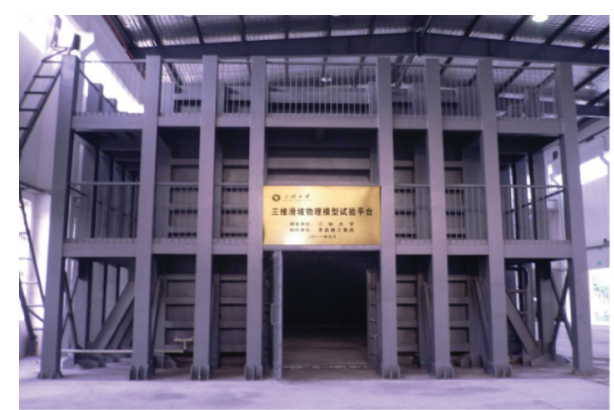

Figure 1: Physical model test framework.

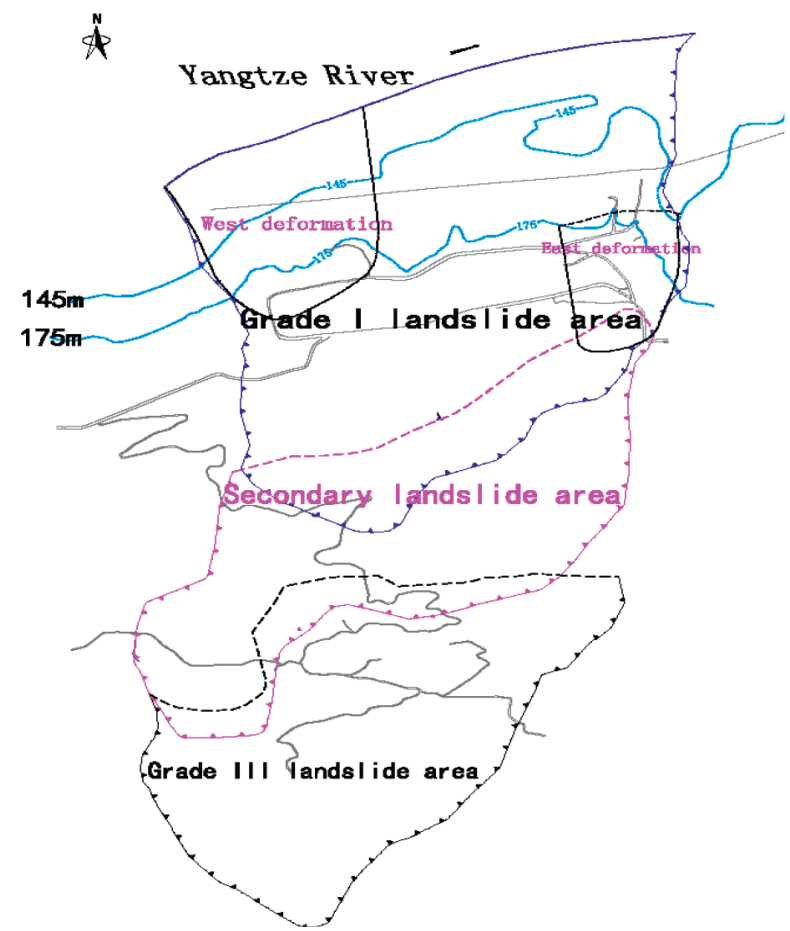

Figure 2: Sketch of plane of Outang landslide.

In order to explore the law of deformation and failure, under ice-snow melting and water-level rise, which give birth to a new born reservoir landslide of the typical bedding accumulation body in the Three Gorges Reservoir Area, this paper selected the Outang landslide as the research object. According to the test purpose, test method, and test conditions, the prototype is generalized. The generalization objective contains the geological structure generalization and the environmental condition generalization.

\subsubsection{Geological Structure Generalization. Selection of} landslide test section. The deformation and failure of the Outang landslide is shown with the 3D characteristics in space. The whole structure data of slope is analyzed using multistation 3D laser scanning technology. Based on digital simulation test, select $\mathrm{A}-\mathrm{A}^{\prime}$ profile, shown in the Figure 3. Based on borehole data, exploration profile data, surface terrain data, surface remote sensing image, reconnaissance engineering, and other design data, the Outang landslide bank slope model was established. The 3D geological generalization model is as shown in Figure 4.

2.2.2. Environmental Condition Generalization. The generalization of environmental conditions changes the external environment of the complex landslide to the controlled model boundary conditions by human. The ice-snow melting and the water level are considered in the model test.

The reservoir water action can be generalized as two processes, which rise from $0 \mathrm{~cm}$ to $100 \mathrm{~cm}$ by the rate of $25 \mathrm{~cm} / \mathrm{h}$ and stabilize the reservoir water level at $100 \mathrm{~cm}$. The effects of reservoir water in front of the landslide are infiltration, erosion, scouring, erosion, deformation, and destruction.

The physical mechanical properties of the soil are weakened by the immersion of reservoir water, which is the front edge of the bank slope. Soaking in reservoir water and soil mass seepage are affecting the stability of reservoir landslide [35].

The effect of ice-snow melting infiltration (total amount, rate, and duration of ice-snow melting) on slope infiltration, runoff generation, and soil seepage erosion creep deformation.

2.2.3. Model Test Theory. The model test theory mainly includes the following four parts:

(1) Model similarity theory and similarity criterion

(2) The method of determining and optimizing the model similar materials

(3) Noncontact measurement technology and method

(4) Model distortion correction method

The formation of landslide is a comprehensive action of internal and external factors. The main internal factors are the physical mechanical parameters of the slip body and the slip material. The similarity theory of the landslide model should be satisfied in many aspects, for example, geometric dimensions, boundary conditions, load density, strength, deformation, and hydraulic characteristics of similar materials.

The geometric similarity coefficient $C_{1}$ is determined by combining the landslide prototype size and model groove size. $C_{1}$ is equal to 175 . As for dimensional analysis, the pattern can be written as follows:

$$
\begin{aligned}
& C_{g}=C_{\rho}=C_{\varphi}=C_{\mu}=1, \\
& C_{t}=C_{q}=C_{v}=C_{k}=175^{1 / 2}, \\
& C_{1}=C_{c}=C_{\sigma}=C_{u}=175,
\end{aligned}
$$

where $C_{g}$ is the gravitational similarity coefficient; $C_{\rho}$ is the density similarity coefficient; $C_{\varphi}$ is the internal friction angle similarity coefficient; $C_{\mu}$ is Poisson's ratio similarity coefficient; $C_{t}$ is the time similarity coefficient; $C_{q}$ is the snowfall similarity coefficient; $C_{v}$ is the velocity similarity coefficient; $C_{k}$ is the infiltrate similarity coefficient; $C_{l}$ is the geometry similarity coefficient; $C_{c}$ is the cohesion similarity coefficient; 

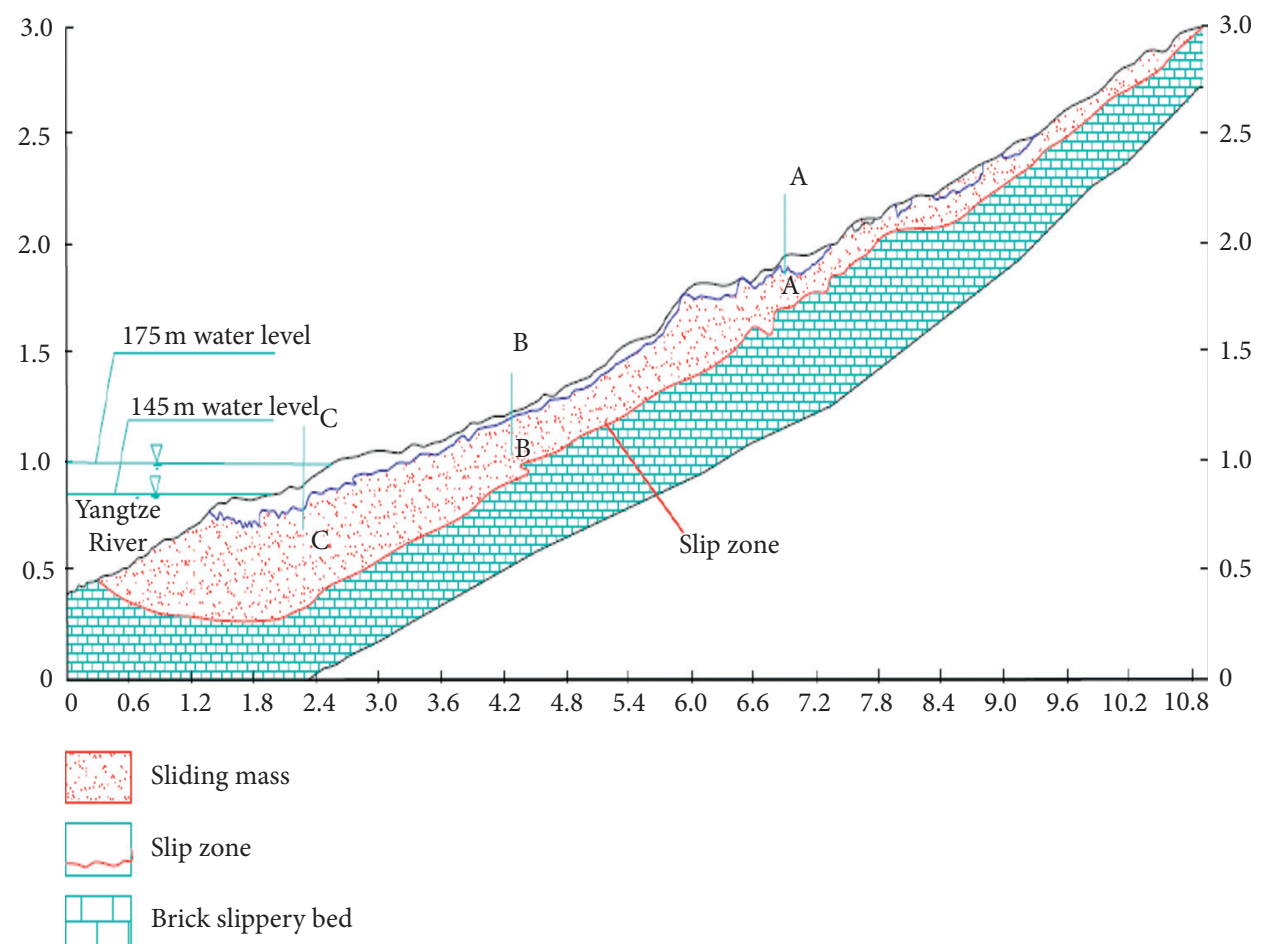

Figure 3: Landslide model section A-A'.

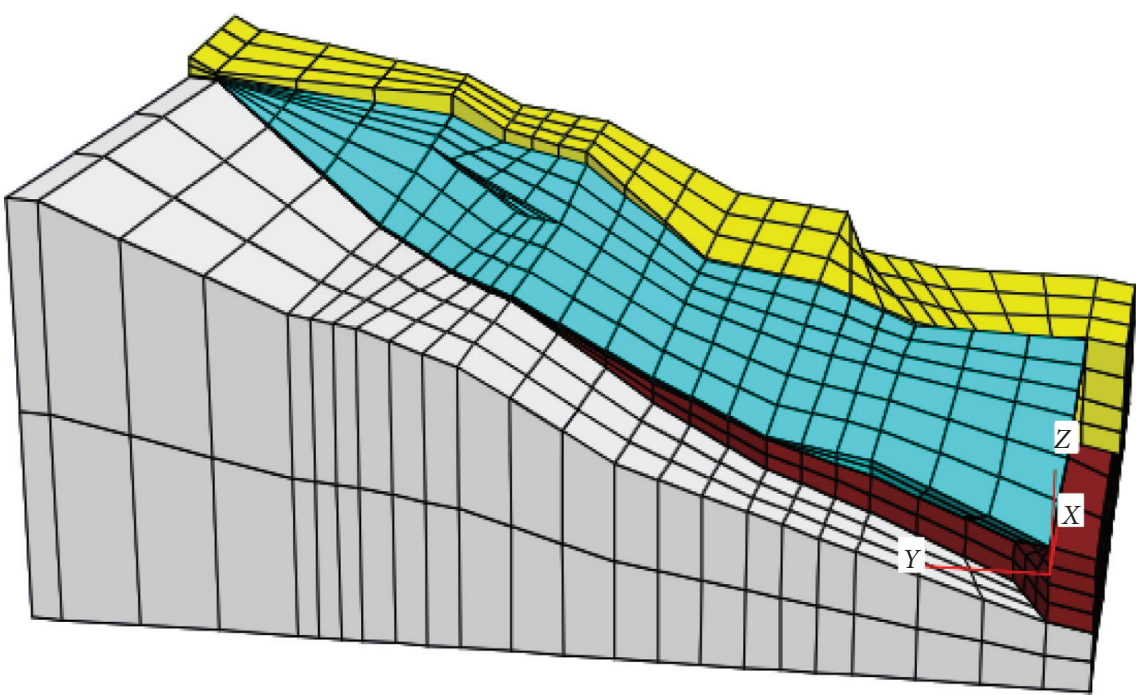

FIGURE 4: The 3D geological generalization model.

$C_{\sigma}$ is the stress similarity coefficient; and $C_{u}$ is the displacement similarity coefficient.

\subsubsection{Model Test Material. Dozens of tons of soil samples} were collected from the site of the Outang landslide. In this paper, the model test uses the actual accumulated soil samples. After the completion of slope filling, the undisturbed soil sample in the slope body is obtained by drilling, with the saturation coefficient measured from the variable water head of $4.3 \times 10-6 \mathrm{~m} / \mathrm{s}$. Several tons of soil samples are successively obtained at the landslide site, all of which are silty clay containing crushed stones $(<10 \mathrm{~cm})$. In order to ensure the reliability and effect of the landslide model test, the basic mechanical test of landslide soil materials should be carried out first. After air drying, crushing, and manual screening of the soil samples on-site, the basic physical tests including density, moisture content, screening, and direct shearing test have been completed successively, and the moisture content, particle grading distribution, and shear strength of the tested soil have been obtained, respectively. Parameters and other physical quantities, together with main test results, are shown in Figure 5 and Table 1.

Physical-mechanical parameters and components of model landslide are shown in Table 2 , where $C_{\rho}, C_{k}, C_{c}$, and 


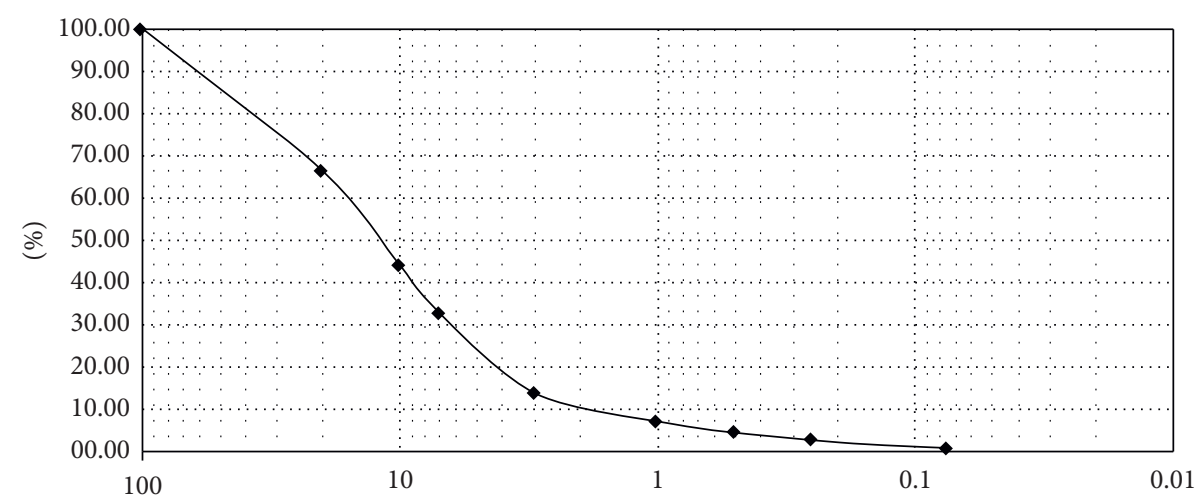

FIgUre 5: Particle size distribution curve.

TABLE 1: Basic property indexes of soils.

\begin{tabular}{lcr}
\hline Symbol & Meaning & Quantity \\
\hline$\gamma\left(\mathrm{km}^{3}\right)$ & Heavy density & 21.4 \\
$\mathrm{k}(\mathrm{m} / \mathrm{s})$ & Permeability coefficient & $2.3 \times 10^{-6}$ \\
$\mu_{0}$ & Poisson's ratio & 0.45 \\
$\mathrm{C}(\mathrm{kPa})$ & Cohesion & 17.2 \\
$\varphi\left({ }^{\circ}\right)$ & Internal friction angle & 18.6 \\
\hline
\end{tabular}

TABLe 2: Physical mechanical parameters and components of model slip zone.

\begin{tabular}{|c|c|c|c|c|c|c|c|c|c|c|c|c|}
\hline \multirow{2}{*}{ Name } & \multicolumn{3}{|c|}{$\left(\mathrm{g} / \mathrm{cm}^{3}\right)$} & \multicolumn{3}{|c|}{$\mathrm{Ks}(\mathrm{cm} / \mathrm{s})$} & \multicolumn{3}{|c|}{$\mathrm{C}(\mathrm{kPa})$} & \multicolumn{3}{|c|}{$\varphi\left(^{\circ}\right)$} \\
\hline & $\mathrm{C} \rho$ & Primary & Model & $C_{\mathrm{k}}$ & Primary & Model & $C_{\mathrm{c}}$ & Primary & $\mathrm{m}$ & $c_{\varphi}$ & Primary & Model \\
\hline Slip zone & 1 & 2.5 & - & $175^{1 / 2}$ & $6.03 \times 10^{-8}$ & - & 175 & 11.5 & $\approx 0$ & 1 & 15.5 & 15.5 \\
\hline Components of the model test slip zone & & & & & g bead: Sma & ll bead: & water & $=34: 16: 5$ & & & & \\
\hline
\end{tabular}

$C_{\varphi}$ are similarity coefficients. The slip zone is made of glass beads with different diameters. The big bead diameter is $10 \mathrm{~mm}$. The small bead diameter is $5 \mathrm{~mm}$. The thickness of the sliding belt in the model test is $50 \mathrm{~mm}$.

\subsubsection{Sensor Layout}

(1) Three longitudinal sections and three transverse sections are arranged at different positions of the landslide to analyze the variation characteristics of the stress field, seepage field, and displacement field, respectively.

In addition, a total of 36 sensors, evenly arranged on the three transverse sections, are installed, including three soil pressure sensors, six earth pressure (thrust) sensors, nine pore water pressure sensors, nine displacement sensors, and nine soil moisture sensors ( $\gamma$-ray method). Setup 9 optical measurement points to observe the changes of earth pressure, pore water pressure, displacement, and soil moisture, respectively.

The C-C profile is located at $230 \mathrm{~cm}$ of the front edge of the landslide. The earth pressure sensor and the pore water pressure sensor are located near the front sliding zone. The corresponding prototype elevation is about $118 \mathrm{~m}$. The displacement sensor is arranged on the surface of the section. The corresponding prototype elevation is about $180 \mathrm{~m}$; soil moisture measuring points, which the corresponding prototype elevation is about $165 \mathrm{~m}$. The elevations of the three noncontact displacement measurement points were respectively set at $170 \mathrm{~m}, 160 \mathrm{~m}$, and $150 \mathrm{~m}$. The sensors on the $\mathrm{B}-\mathrm{B}$ section and A-A section are arranged in accordance with C-C section. See Figure 6 for the specific location.

\section{Test Process and Test Result Analysis}

3.1. Model Test Conditions. During the test, elastic-plastic deformation occurs on the soil body, indicating that the model test was not repeatable. This model test mainly considered the combined action test of ice-snow melting water and reservoir water at the level of $100 \mathrm{~cm}$ under the extreme ice-snow disaster in winter. The similarity ratio of the model test concerning this test platform is $1: 175$. The model test conditions are shown in Table 3.

Before the large-scale three-dimensional model test, the bank slope model was pretreated so that the test soil can reach the initial water content (volumetric water content of $22-24 \%$ ), and the bank slope test soil area was $50 \mathrm{~m}^{2}$. In winter, the operational water level of the Three Gorges Reservoir Area was $175 \mathrm{~m}$, and the reservoir water level of the bank slope in the model test bank slope was set to be $100 \mathrm{~cm}$ correspondently. The ice and snow with a thickness of $30 \mathrm{~cm}$ was evenly laid which was started from 6 a.m. and 


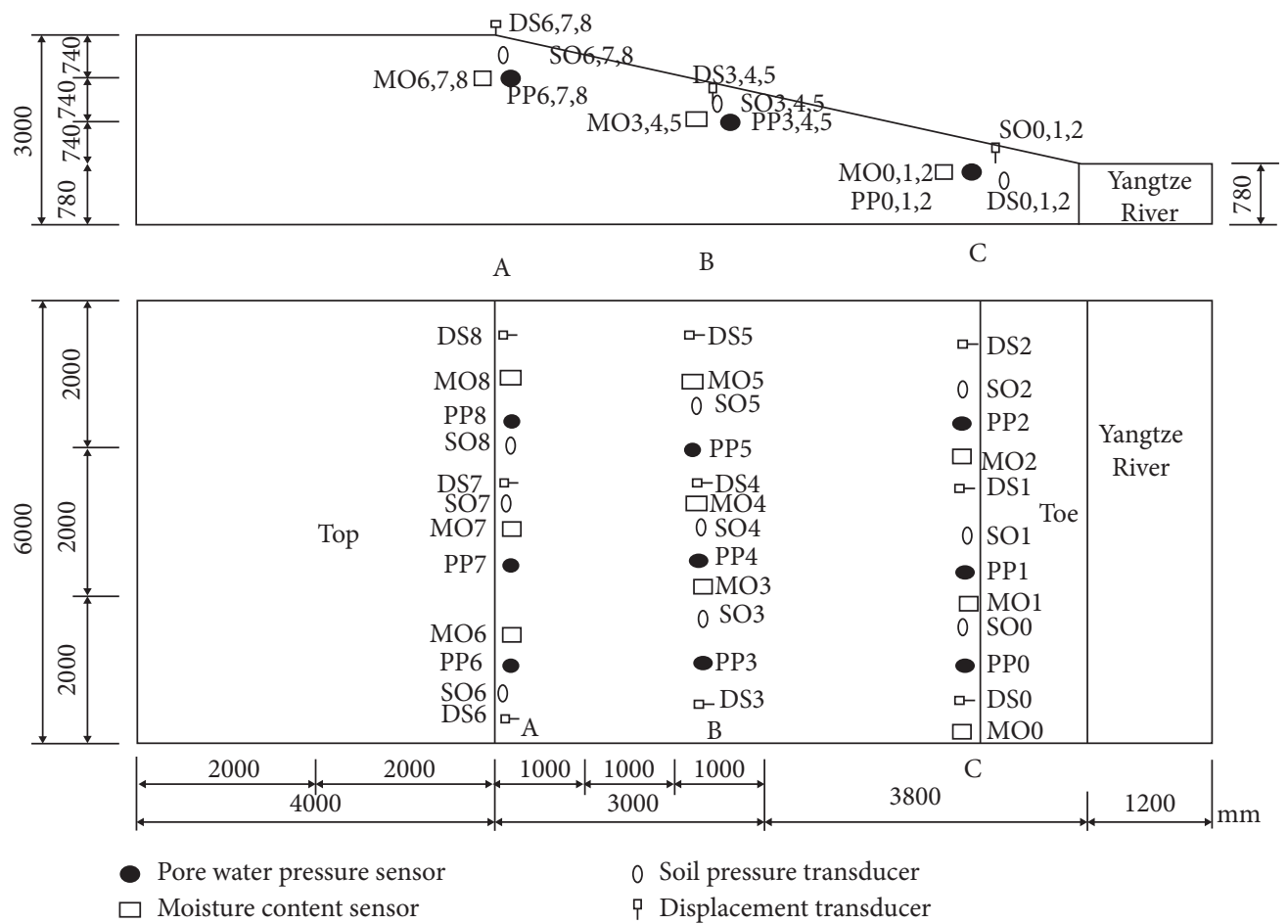

FIgURE 6: Sensor layout.

TABLE 3: Ice-snow melting model test conditions.

\begin{tabular}{ll}
\hline Stage & \multicolumn{1}{c}{ Combination of boundary conditions } \\
\hline & $\begin{array}{l}\text { Time } \\
\text { meet the standard. Stable initial settlement of the bank slope is achieved when the similar }\end{array}$ \\
$\begin{array}{l}\text { Combined action of reservoir water and } \\
\text { ice-snow melting }\end{array}$ & $\begin{array}{l}\text { materials of the bank slope reach the initial volumetric water content of the test, i.e., } \\
22-24 \% ;(2) \text { Evenly pave the ice and snow with a thickness of } 30 \mathrm{~cm} \text { in the } 50 \mathrm{~m}^{2} \text { test bank } \\
\text { slope soil; (3) The water rises at a speed of } 25 \mathrm{~cm} / \mathrm{h} \text { from the bottom }(0 \mathrm{~cm}) \text { of the dam to } \\
\text { the high water level at } 100 \mathrm{~cm} \text {; (4). The water at the high water level of } 100 \mathrm{~cm} \text { in the } \\
\text { model tank is fused with the ice-snow melting water until it completely melts. }\end{array}$ \\
\hline
\end{tabular}

ended at 7 a.m. on February 1, 2019 (the local temperature of the test site at that time was about $\left.0^{\circ} \mathrm{C}\right)$. At this time, the water was slowly stored at the speed of $25 \mathrm{~cm} / \mathrm{h}$ from the bottom $(0 \mathrm{~cm})$ of the reservoir in the model to the water level of $100 \mathrm{~cm}$. During the rising of water level, the front part of the bank slope was gradually submerged by the reservoir water to the position of $100 \mathrm{~cm}$ water level, and microcracks were observed on the soil body at the front edge of the bank slope. At 8 a.m. on February 8, 2019, ice-snow melting was ended, and the combined effect of ice-snow melting water and $100 \mathrm{~cm}$ reservoir water level was made to last for 7 days, about 170 hours. The deformation process of the reservoir bank slope under the above effect is shown in Figure 7. The high water level had been maintained for 15 days until 8 a.m. on February 16, 2019.

\subsection{Volume and Rate Calculation of Indoor Ice-Snow Melting.} In this test, the thickness of bank slope soil is about $1.5-2.0 \mathrm{~m}$ and that of slope top is $1.5 \mathrm{~m}$. It is evenly laid according to the actual slope shape trend from the top to the toe of the slope, and the maximum thickness of the middle is $2.0 \mathrm{~m}$. Seven tons ice and snow is laid in total. The surface area of the bank slope is $50 \mathrm{~m}^{2}$, with an average thickness of ice and snow to be $30 \mathrm{~cm}$. The 24-hour temperature of the slope surface is strictly recorded; we have calculated snow melting rate and intensity by temperature difference. The ice and snow melts completely in 7 days, while $80 \%$ of the total amount of ice and snow melts in the first 5 days, with the rate of $1.1 \mathrm{~T} / \mathrm{d}$, namely, $46 \mathrm{~kg} / \mathrm{h}$ or $0.76 \mathrm{~kg} / \mathrm{min}$. The density of ice and snow used in the model test is $0.5 \times 10^{3}-0.6 \times 10^{3} \mathrm{~kg} / \mathrm{m}^{3}$, and the slope angle of the model test landslide is $26^{\circ}$. The $30 \mathrm{~cm}$ thick ice and snow laid on the soil mass of the bank slope is the ice sheet waiting for gradual melting, and the load applied to the soil body of the bank slope equals to that of 7T water in the water tank gradually falling on the bank slope.

3.3. Model Boundary Conditions. In this paper, the transient seepage field of slope changed by water level. The sliding surface is a barrier boundary, that is, zero flow boundary. 


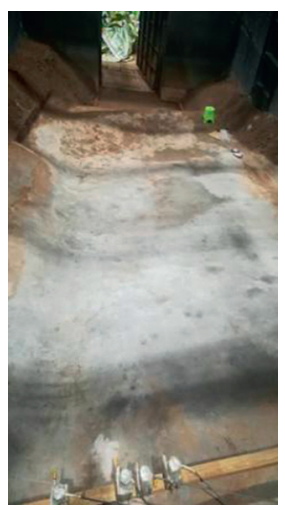

(a)

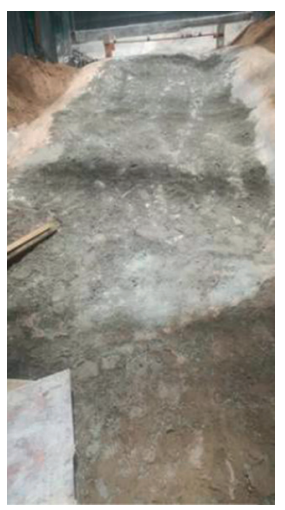

(b)

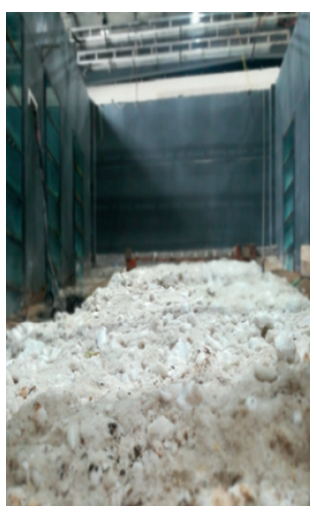

(c)

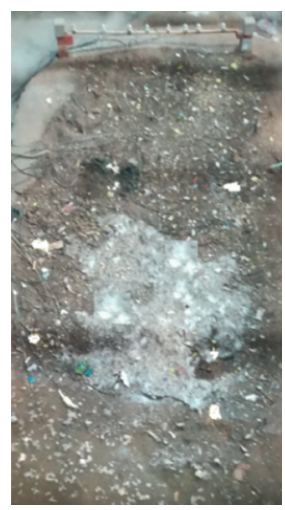

(d)

Figure 7: Deformation process of bank slope. (a) Bedrock pouring. (b) Sliding belt laying. (c) Snow heaping. (d) Ice-snow melting.

The boundary of constant head is below the water level. The infiltration process of ice-snow melt water is essentially a process of snow water migration and deformation in the unsaturated region. The infiltration is the boundary of soil water flow.

The shallow sliding mass has a very good permeability in the east and west of the Outang landslide. The groundwater and the reservoir level has the same change trend, and the deformation is large. The sliding belt has soaking effect quite obvious by reservoir water. The anti-slide force is obviously reduced. The broken soil has adjust stress. The creep deformation has occurred at the potential bedding slip surface. The model failure mainly occurred in the soil at a depth of $80 \mathrm{~cm}$. The soil has strong permeability. The seepage characteristic is unsaturated vertical infiltration. The failure mode is unsaturated shallow failure [36], and surface runoff also occurs.

3.4. Test Response of Ice-Snow Melting Infiltration. The matrix suction of the unsaturated zone decreased gradually as ice and snow continuously melted, followed by gradual decrease in the overall stability of the slope and gradual increase in both horizontal and vertical displacement of the slope surface. The deformation showed that the deformation of the front edge was larger than that of the back edge in the horizontal direction, and the back edge in the vertical direction was downward staggered, while the front edge was uplifted. With the infiltration of snowmelt water and increase in the pore water pressure of the slope, the effective stress of the soil decreased, accompanied by simultaneous decrease in the shear strength of the soil and the stability of the slope. The deformation of the bank slope under ice-snow melting is shown in Figure 8. At this time, the load effect of ice-snow melting water can be divided into the following three processes:

(1) At the beginning of snowmelt infiltration, the snowmelt water infiltrated into the slope body, leading to gradual increase in the water content of the slope soil on the surface layer from the initial water content, and the snowmelt water colored by faint yellow was discharged out of the slope body about 24 hours later. After 48 hours, the water content of the surface soil reached the saturated water content. During the first 48 hours, the advancing trend of the wetting front was parallel to the soil slope. After 72 hours, the wetting front started to move downward in a semielliptical shape and the unsaturated soil at the lower part of the bank slope got saturated. At the 96th hour, the soil at the depth of $30 \mathrm{~cm}$ of the soil slope reached saturation, and the vertical depth of the wetting front then gradually reached $40 \mathrm{~cm}$. Subsequently, the seepage expanded to $50 \mathrm{~cm}$ along the slope direction, and the internal saturation line of the bank slope steadily moved down.

(2) The respective water content at the depth of $30 \mathrm{~cm}$ and $40 \mathrm{~cm}$ at the top, middle, and near the foot of the slope changed rapidly. After 10 days of ice and snow melting, the above water content slowly decreased and gradually stabilized, among which there were minor differences. However, the water content in the foot at the depth of $50 \mathrm{~cm}$ changed obviously and increased to some extent after snowmelt water infiltration stopped. The increase in water content was attributed to the continuous infiltration caused by the hysteresis of the water content of the upper soil. In addition, a large range of transient saturation area may appear in the gentle slope zone and the slope foot.

(3) After $120 \mathrm{~h}$, the infiltration peak of ice-snow melting water gradually slowed down and the water content increasing rapidly in the saturated area of the slope gradually stabilized with weakening characteristics. Here, occurred a lag effect during the infiltration process. The seepage of the wetting front and along the slope direction expanded, followed by continuous soil softening and swelling of slope foot soil with a speed significantly lower than that at the peak of snowmelt.

Snow melting intensity is closely related to the failure mode of landslide. The variation of pore water pressure with snow melting intensity is different at different depths 


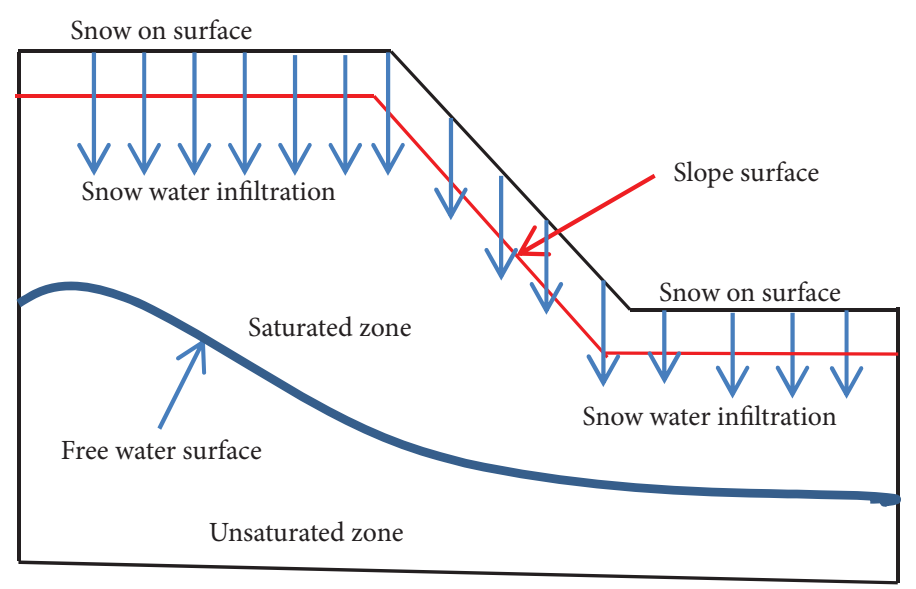

(a)

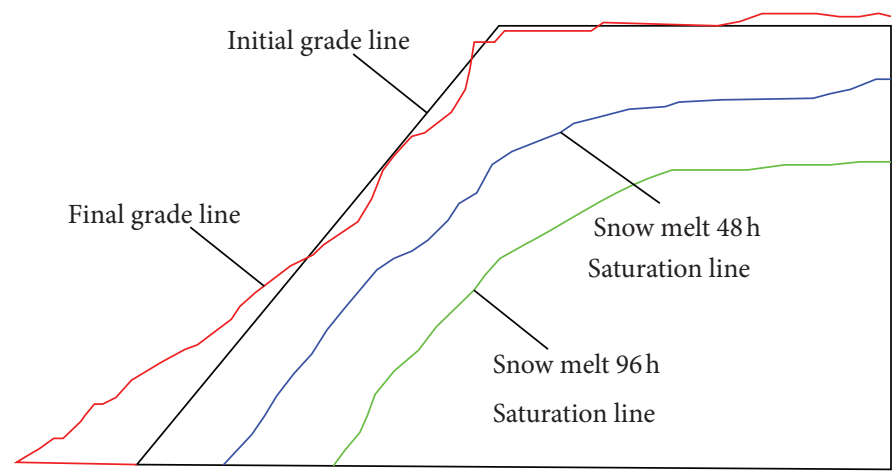

(b)

FIGURE 8: Schematic diagram of seepage erosion deformation under ice-snow melting. (a) Schematic diagram of ice-snow melting on bank slope. (b) Schematic diagram of infiltration line of ice-snow melting.

in the same section. The response time of pore water pressure to snow melting intensity is positively proportional to the snow melting intensity. When the snow melting intensity is $0.0116 \mathrm{~kg} / \mathrm{min} . \mathrm{m}^{2}$, the soil will flow at the foot of the slope; when the snow melting intensity is $0.0128 \mathrm{~kg} / \mathrm{min} . \mathrm{m}^{2}$, the failure mode of the landslide is that the slope toe starts to form multistage backward shallow creep deformation step by step. When the snow melting strength is $0.0152 \mathrm{~kg} / \mathrm{min} . \mathrm{m}^{2}$, the landslide mass will creep along the most dangerous shear plane and eventually form plastic creep flow.

\subsection{Test Response of Combined Action of Ice-Snow Melting and} Reservoir Water. The $100 \mathrm{~cm}$ reservoir water level can submerge $19.2 \%$ of the bank slope in the model test. With the combination of the above water level and ice-snow melting, the infiltration produced a continuous seepage force to the outer side of the slope and the cracks at the foot and front edge of the bank slope expanded, deepened, and infiltrated continuously. Cracks and settlement of the front edge of the bank slope occurred, resulting in the slump deformation. The process curve of measured values changed with time of each sensor under the condition of combined action of ice- snow melting and reservoir water, based on the distortion model and correction method of distortion [37], as shown in Figure 9. The sensor takes reading every 10 minutes.

The conclusions are presented as follows:

(1) The volumetric water content of ice-snow melt water is higher than $35 \%$. The change of each water content sensor is significant, and the values of all water content sensors are increased. After a certain period of time, the wetting front reaches the monitoring point and the water content gradually increases to the peak value and tends to be stable. The water level of the reservoir rises slightly with the increase in snowmelt.

(2) As shown in Figure 9(b), the pore water pressure increases until it reaches saturation and is generally stable under the condition that the soil mass on the bank slope below the water level of $100 \mathrm{~cm}$ turns to be saturated gradually after a certain period of immersion. However, the pore water pressure of the soil above the water level of $100 \mathrm{~cm}$ is always negative, which indicates that the saturation range of ice-snow melt water is relatively shallow at the beginning of the infiltration, and the soil of the depth, to which the pore water pressure sensor is 


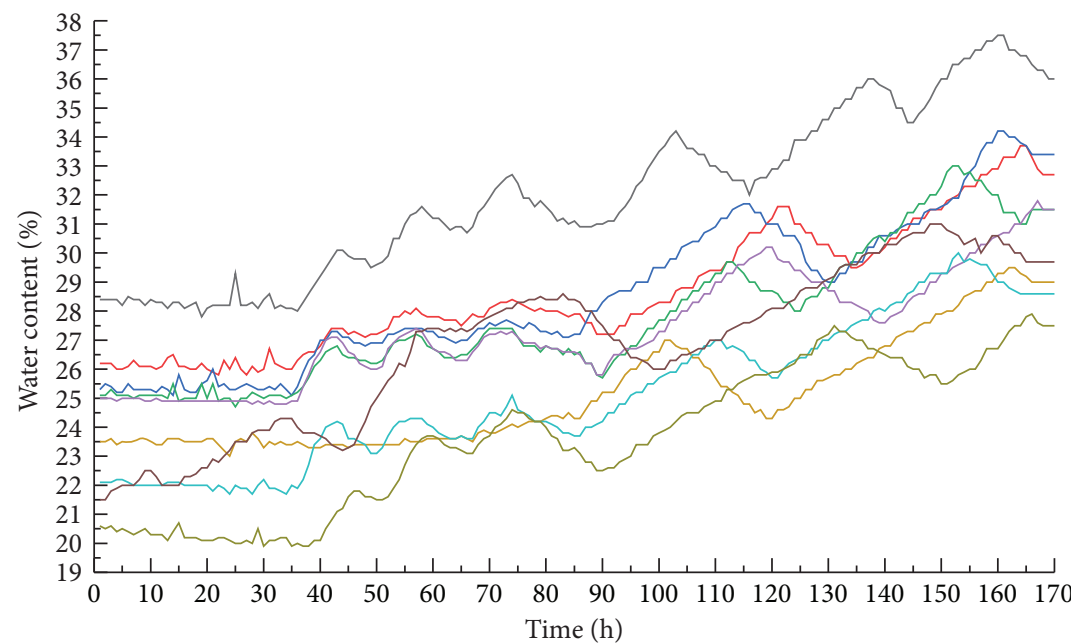
-0
-1
$-\quad 2$
-3
$-\quad 4$
-5
-6
-7
-8

(a)

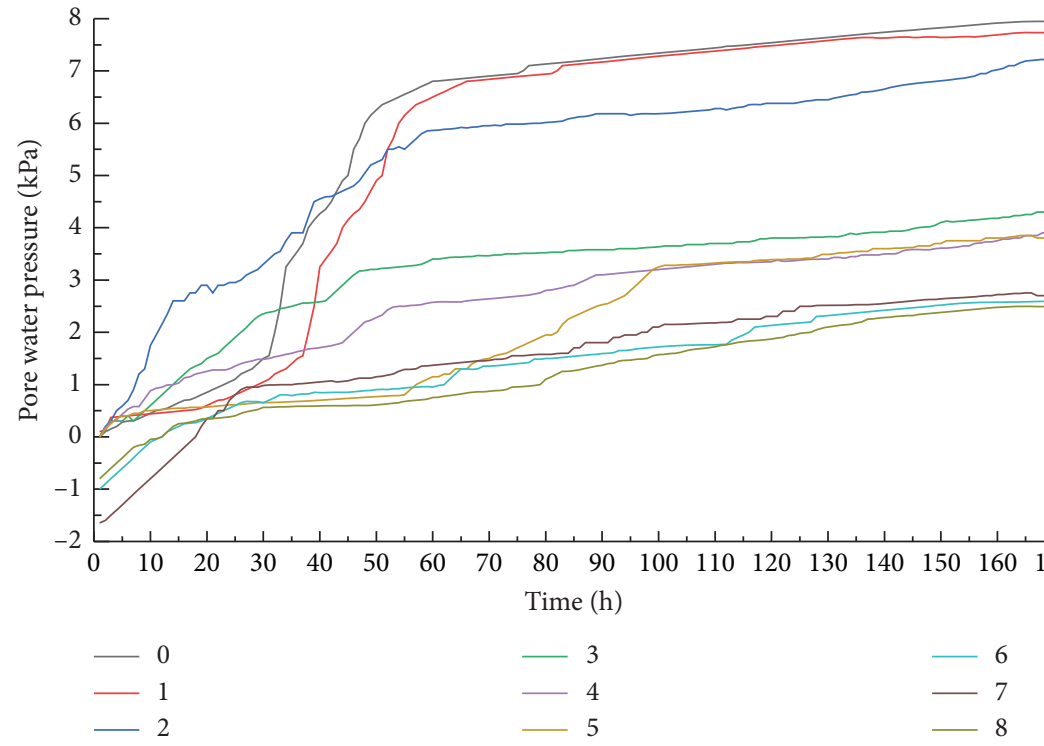

(b)

Figure 9: Continued. 


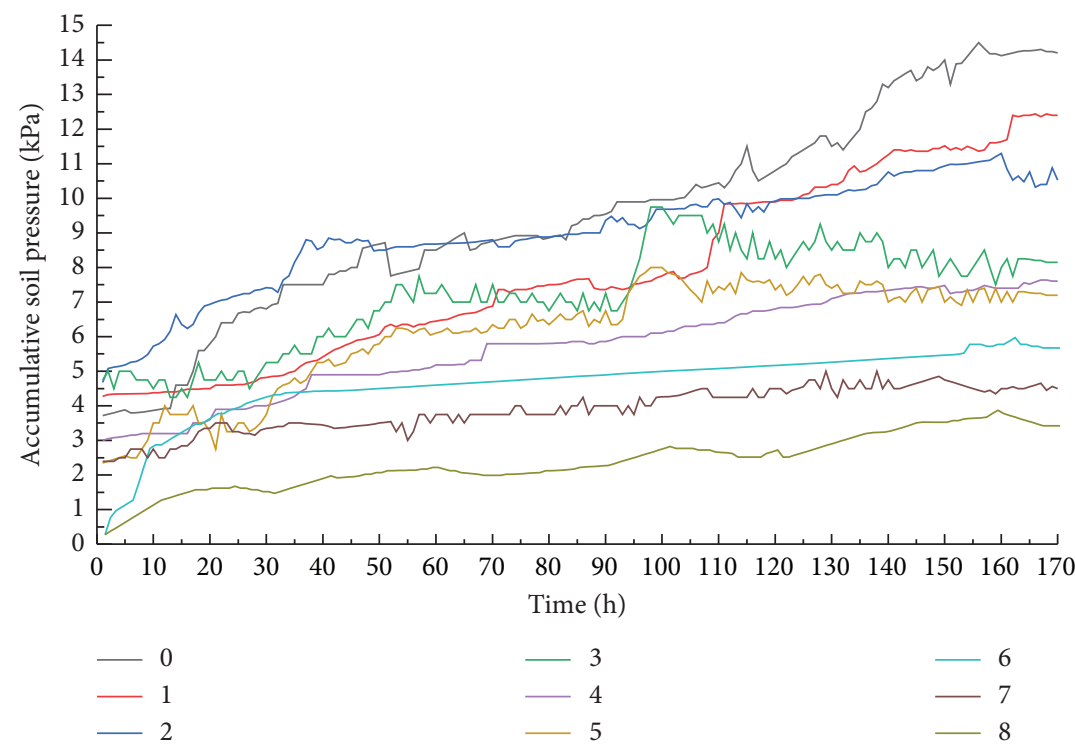

(c)

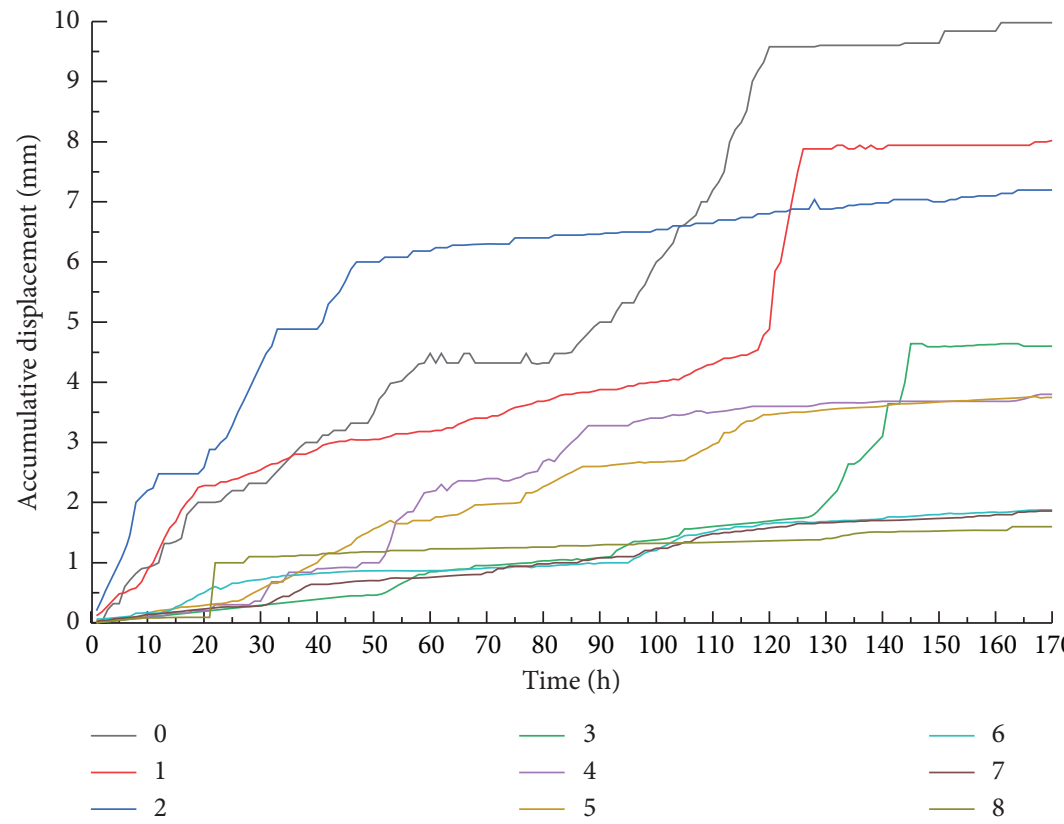

(d)

Figure 9: Change curve of sensor. (a) Change curve of moisture content sensor. (b) Change curve of pore water pressure sensor. (c) Change curve of soil pressure sensor. (d) Change curve of horizontal displacement sensor.

buried, is not completely soaked. With the continuous infiltration, the pore water pressure above the $100 \mathrm{~cm}$ water level gradually approaches to 0 from the negative value and the saturation range of snowmelt infiltration is gradually expanding. The change of pore water pressure at the measuring point increases with the rise of reservoir water level, and the change of pore water pressure lags slightly. From the monitoring data of the sensor, it can be seen that the time when the pore water pressure measuring the $\mathrm{C}-\mathrm{C}$ profile has the fastest maximum response pore water pressure, the $\mathrm{C}-\mathrm{C}$ profile has the fastest response. Maximum pore water pressure. The gentle middle part is favorable for snow water infiltration. The seepage formed by hydraulic gradient has pointed to the middle and front of bank slope. The A-A section in the rear edge is slightly behind the $\mathrm{B}-\mathrm{B}$ section. The pore water pressure near the slip zone is positively proportional to the response intensity of snow melting. When the snow melting intensity is higher, the variation curve of pore water pressure is always above of the middle 
and back. The ice-snow is melting quickly day and night. The slope surface temperature is $0.1^{\circ} \mathrm{C}$ at $1: 00$ a.m. in the evening, and the amount of ice-snow melting is very small. At this time, the slope is partially drained. There are many groups of cracks in the surface soil, and they form dominant infiltration channels. After noon tomorrow, the melting intensity and the infiltration rate increased.

(3) It can be seen from Figure 9(c) that the soil thrust increases rapidly during the peak period of snowmelt. The change of soil pressure, slightly lagging behind, increases with the rise of reservoir water level.

(i) At this time, the soil body at the depth of $80 \mathrm{~cm}$ on the surface of the bank slope is completely saturated. The sliding thrust at the front end of the slope can reach the peak value under the action of ice-snow melt water, which causes softening and strength reduced of the soil. After 96 hours of snow melt water infiltration, the sliding force of the No $4 \#$ soil is greater than its anti-sliding force, and the soil near the soil thrust sensor is unstable, as shown in Figure 10(a).

(ii) The bank slope began to store water, and the slope toe was partially creeping and deformed. The earth pressure sensors of No 0\# and No 2\# at slope toe decreased in a small range. There are two main reasons:

(1) The soil at the foot is carried away by the scouring of reservoir water and snow water, resulting in local soil flow, which leads to the reduction of the density $l$ and the earth pressure.

(2) Sliding failure occurs in the front soil, and the squeezing force is reduced by soil. This will lead to the decrease in earth pressure.

(iii) The leading edge accumulation body is partially penetrated and dislocated, as shown in Figure 11(b). No 0\#, No 1\#, and No 2\# earth pressure sensor. A large amount of snow water enters the cracks, resulting in the increase in soil bulk density, and the earth pressure obviously increases when the snowmelt intensity further increases. Finally, it leads to plastic flow. The earth pressure will decrease slowly with the loss of surface soil.

(iv) When reservoir water level rises, the reservoir water infiltrates into the slope, the soil bulk density increases, the Earth pressure gradually increases, and the total stress of soil increases. The slope surface temperature is $0.1^{\circ} \mathrm{C}$ at $1: 00 \mathrm{a} . \mathrm{m}$. in the evening, and part of the water in the slope is discharged along the seepage channel. The soil bulk density decreases, and the earth pressure decreases slowly, as shown in Figure 9(c). The response of soil pressure to snow melting rate is consistent with that of pore water pressure. We can see that the higher the melting rate, the faster the infiltration; the increasing trend of earth pressure become more obvious.
(4) With the continuous development of reservoir water and snow melting, the surface displacement increases rapidly, as shown in Figure 9(d). Cracks of different scales appear in the slope, especially at the junction of ice-snow and reservoir water in the middle-front part. After 4 days, combined action of reservoir water and ice-snow melting occurs at the junction of ice and water in the middle and front. The disturbance is affected by the speed of ice-snow melting alternately. The $300 \mathrm{~cm}$ long crack was appeared, as shown in Figure 11(a). The No 3\#and No 4\# soil pressure sensors will increase significantly located in the failure area. When the intensity of snow melting increases, the plastic flow will eventually occur. The earth pressure will decrease slowly with the loss of surface soil.

From displacement monitoring curve, the deformation of slope has obvious zoning in time and space. At time, the deformation development is mainly concentrated after the saturated deformation of the shallow soil (continuous icesnow melting $50-110 \mathrm{~h}$ ). The slope has no obvious large deformation failure. In space, the front edge becomes deformed severely and the deformation caused displacement, respectively, $7.56 \mathrm{~mm}$ and $9.93 \mathrm{~mm}$; the middle part was $3.95 \mathrm{~mm}$ and $2.93 \mathrm{~mm}$, and the posterior edge was only $1.2 \mathrm{~mm}$ and $1.15 \mathrm{~mm}$. So, the large deformation occurs in the leading edge and middle. Combined with the displacement monitoring curve, it can be seen that there is a corresponding relationship between the change of soil pressure and the development of slope deformation.

\section{Seepage-Erosion-Deformation Process within Physical Model Test}

The ice-snow melting is more likely to occur in the erosion deformation of the soil mass inside the bank slope. The variation of fine particles content in the soil skeleton is due to the ice-snow melting.

The shallow sliding mass in the east and west of the Outang landslide has good permeability. The change trend of groundwater level and reservoir level is synchronous, and the deformation is large. The soaking softening effect of reservoir water on sliding belt is quite obvious. The anti-slide force is obviously reduced. Creep occurs along the potential bedding slip surface due to stress adjustment. The shallow deformation areas in the east and west are seriously affected by the melting water of ice and snow. The deformation on the west side of the front edge is the most serious.

In this paper, the model test has two working conditions.

(1) Failure process on the west side of the front edge under the single action of ice-snow melting

(2) The transverse crack deformation in middle front under the combined action of reservoir water and ice-snow melt water

In this paper, the model test is characterized by creep deformation instability. 


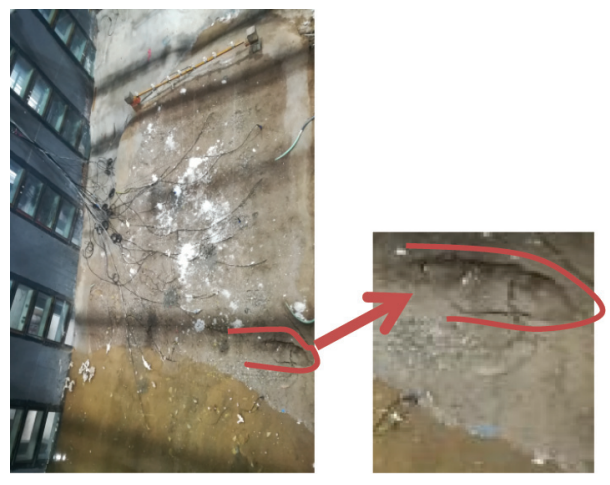

(a)

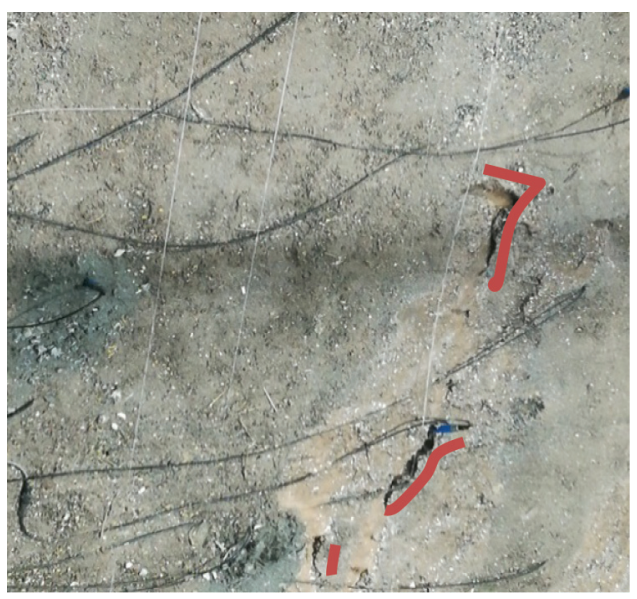

(b)

Figure 10: Deformation under the ice-snow melting. (a) Deformation-failure on the left side of the front edge. (b) Longitudinal cracks on a sliding surface.

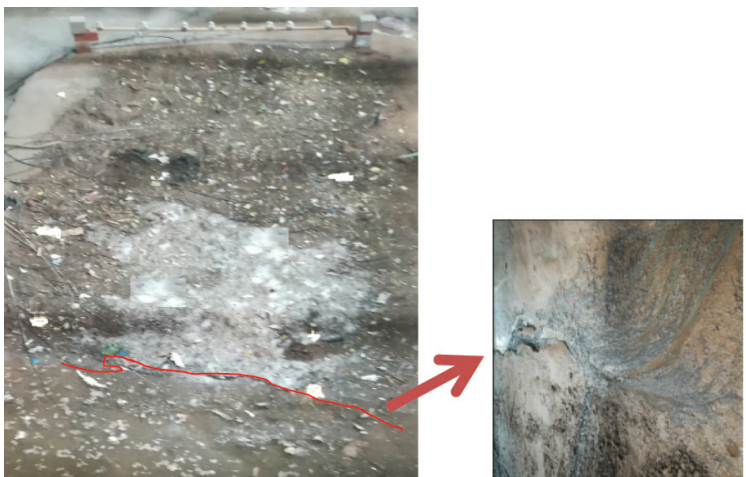

(a)

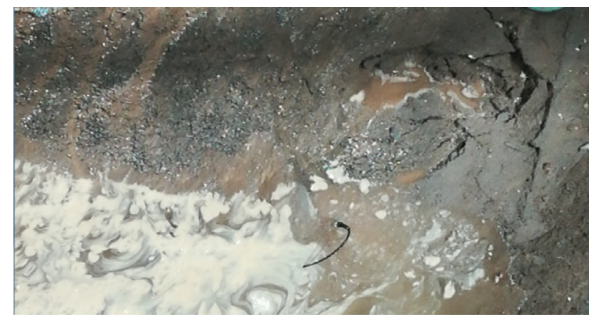

(b)

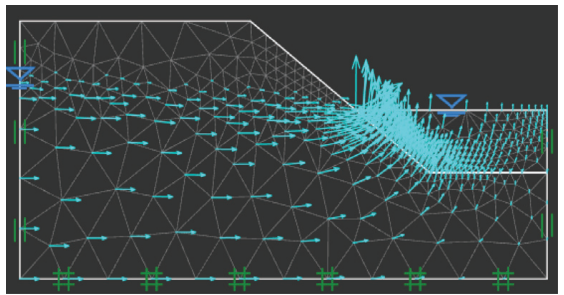

(c)

Figure 11: Bank slope damage under the combined action of reservoir water and ice-snow melting. (a) Deformation of slope surface. (b) Part of the destruction. (c) "Water hammer" mechanism reflected.

4.1. Seepage Erosion Equation of Soil. The soil matrix of soils susceptible to suffusion is usually composed of mixed coarse and fine particles. Under certain geometric and hydromechanical conditions, the fine particles can be detached from the solid skeleton and behave as a part of the liquid phase in the form of liquidize fine particles, which can be transported away by the flowing liquid. To describe this fines migration process, unsaturated soils composed of mixed coarse and fine particles with their pore spaces filled by liquid or air are treated as a kind of three-phase multispecies porous media [38]. The loss of fine particles in the soil of bank slope leads to the change in microstructure of the soil. The nonlinearity of the permeability coefficient is a typical characteristic of the soil subjected to seepage erosion on the microscale. The overall erosion deformation of the bank slope surface is shown in Figure 12. Based on the theory put forward by Sterpi [39], the relationship between the density $\rho_{\mathrm{e}}$ of erosion fine particles and the hydraulic gradient and time is established in accordance with the model test results. The erosion equation can be expressed as follows: 

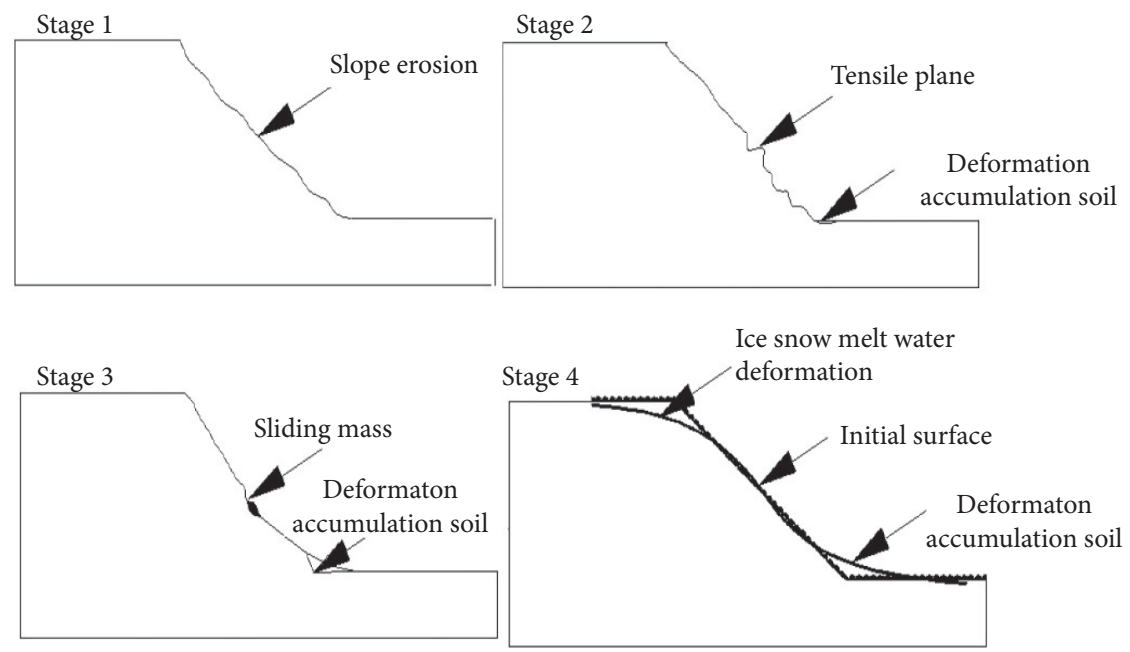

Figure 12: The evolution process of local shallow sliding deformation of bank slope.

$$
\rho_{e}=\rho_{0}\left[1-\exp \left(-\left(\frac{t}{t_{0}}\right)^{n} \cdot \frac{i^{p}}{m}\right)\right],
$$

where $\rho_{0}$ is the initial fine particle mass density (mass of fine particles per unit volume, $\left.\mathrm{kg} / \mathrm{m}^{3}\right) ; t_{0}$ refers to $1 \mathrm{~h}$; and $m, n$, and $p$ are all dimensionless test parameters. Equation (2) shows the response of the density for eroded fine particles under the condition of hydraulic gradient and time.

\subsection{Failure Process of Slope Under the Single Action of Ice-} Snow Melting. The single action of ice-snow melting can be included with two working conditions. On the one hand, there is no water storage at the bottom of the reservoir. During the one-hour snow spreading from 6:00 to 7:00 in the morning of February 1, the ice and snow changed dynamically and the load gradually increased. On the other hand, the water rose from the bottom $(0 \mathrm{~cm})$ of the dam at the speed of $25 \mathrm{~cm} / \mathrm{h}$ to the high water level at $100 \mathrm{~cm}$ within 4 hours from 7:00 a.m. to 11:00 a.m.

In the process of numerical simulation of unsaturated soil seepage, the following two aspects are mainly involved:

(1) The permeability coefficient of the joint is adjusted by obtaining the saturation of the joint.

(2) The relationship between matrix suction and water content in the process of soil moisture absorption and dehumidification is simplified to the same function, and the relationship between matrix suction and soil saturation can be thus obtained. The deformation of the leading edge on the left is shown in Figure 10.

Since an impermeable bottom is assumed for the slope, water can accumulate once reaching this boundary. At time $t=0.5 \mathrm{~h}$, positive water pressure can be observed near the toe of the slope, and plastic shear strains begin to develop near this region. Along with the water infiltration, plastic shear strains develop and accumulate with time. At time $t=1 \mathrm{~h}$, continuous localized plastic shear strains can be observed through the slope, which represents that a continuous slip surface has been developed. Slight deformation took place, and the failed mass starts to move downwardly under gravity.

Simulation of coupled seepage-erosion-deformation process within slopes. Soils in landslide deposits show the geometrical features which are susceptible to internal erosion under ice-snow melting infiltration. Upon seepageinduced erosion, fine particles will be transported from the middle part and surface of the slope to the toe and deeper part of the slope. The fines migration process will inevitably alter the characteristics of slope soils, which influences both the failure mechanism and the post-failure motion of the slope. The ice-snow melting induced failure process of an unsaturated slope comprised of soils prone to internal erosion is simulated with the coupled seepage-erosiondeformation.

The slope model contains 10,240 material points which are distributed uniformly in a background grid of three material points per cell with the cell size of $1 \mathrm{~mm} \times 1 \mathrm{~mm}$. Both the right and left sides of the material point domain are prescribed with boundary for both solid and liquid phase, which prevents horizontal displacement and liquid flow; a fully fixed boundary for both solid and liquid phase is prescribed at the bottom to simulate a perfectly rough interface with the impermeable bedrock below; zero pore liquid pressure and concentration boundary conditions are assigned on the slope surface to trigger clean snow melting infiltration.

Retrogression can be observed after the full saturation of the slope. By using the analog computation coupled seepageerosion-deformation, the evolution of mass fraction of erodible fine particles and the volumetric concentration of liquidized-fines particles can be obtained. As can be seen, the internal erosion process developed along with the infiltration process, which led to severe fine particles decrease near the slope surface. Meanwhile, liquidized-fines particles are generated along with the erosion process, which are then 
transported along with the flowing fluid toward the interior slope.

\subsection{The Deformation under the Combined Action of Reservoir} Water and Ice-Snow Melt Water. The infiltration process of ice-snow melt water is simulated by adopting the saturatedunsaturated seepage analysis module, flow boundary conditions, and transient analysis method. The calculation results are saved every 10 minutes in the early stage of icesnow melt water and every 30 minutes in the middle and later stages, with the pore water pressure at the monitoring point recorded in real time simultaneously.

This paper analyzes the stability of the slope. The distribution of the seepage field and the location of the infiltration line in the slope are unknown. The only information given is that the infiltration line is exposed at the foot of the slope, and it is under the condition of still water at $100 \mathrm{~cm}$. For the reservoir water at $100 \mathrm{~cm}$ and ice-snow melt water, the lower limit element type and upper limit element type are adopted, respectively. Furthermore, 10,240 elements and 3 grid adaptive iterations are adopted. As a part of the whole analysis, the calculation of seepage field is automatically done by the software. In addition, when seepage is introduced into the analysis, variables related to the seepage field are included in the adaptive control variables.

The model process of unsaturated soil seepage is as follows:

(1) Set the basic seepage material parameters. Set the icesnow infiltration boundary on the membrane unit, and set the water infiltration value according to the measured snow water intensity.

(2) The saturation of the unsaturated grid nodes is obtained by the built-in program language of the program, and then the matrix suction of the corresponding nodes is calculated by the fitted matrix suction formula, followed by the negative pore water pressure of the nodes assigned.

(3) The saturation of the element can be calculated by the weighted difference method on the basis of the node saturation obtained from the previous step based on which the relative permeability coefficient of the element is calculated and then assigned to the corresponding element.

(4) Through the above correction of pore water pressure and permeability coefficient and traversing all nodes in this way, the seepage of unsaturated soil can be realized.

The seepage calculation of unsaturated soil can be carried out through the above four steps where the saturation is taken as the judgment basis for calculation. In specific, when the node saturation is less than 1 , it shows that the node is in an unsaturated state, and the matrix suction and permeability coefficient can then be calculated by the above formula and assigned to the corresponding node unit; as the snow water infiltration soil gradually saturates, the pore water pressure of the saturated soil can be calculated according to the seepage, and the permeability coefficient of the saturated soil is then a constant value. Soil deformation of the slope surface at the snow and water interface is shown in Figure 11.

During the test process, the existence of cracks in the slope body was observed. Therefore, elements with cracks are set in the slope body. According to numerical simulation, the failure process and the change processes of pore water pressure and horizontal soil pressure of the slope can be obtained. The specific analysis results are illustrated in Figure 11(b).

It can be seen from the above that the soil mass of the slope has large transverse cracks on the surface at the front and middle of the ice and water junction, and the bank slope has been damaged. In the failure area, the isocline of soil pressure in horizontal direction is relatively dense, which indicates that the soil pressure in horizontal direction in this area changes significantly; when the slope is damaged, the horizontal soil pressure of soil near the sliding zone changes greatly and the isocline is relatively dense, which is caused by the failure of the soil in this area and the transition of the stress between the soil in the damaged area.

During the rise of reservoir water at the front edge, the part with the largest impact on the slope is the front part where the water can penetrate. There is little change in the readings of the pressure sensors at the back edge and no hydrodynamic pressure. In the process of reservoir water rising, the hydrodynamic pressure and normal stress gradually increase. In the process of reservoir water rising, cracks are produced step by step, and the front slope appears creep, but no large-scale sliding occurs.

The hydraulic gradients of combined action of reservoir water and ice-snow melting as well as the velocity fields are homogenous along the depth; therefore, homogenous erosion rates will be generated. In addition, the fine particles inside soils will be eroded until the fine content fraction reaches the ultimate fine content fraction which is also dependent on the ice-snow melting seepage velocity.

The horizontal and vertical displacements gradually increase infiltration with the ice-snow melting. The influence area of snow melting infiltration on slope seepage field is concentrated in the slope toe and slope center; that is, the area formed by transient saturation region preferentially. The vector concentration at the toe of the slope means that obvious slip deformation has taken place. At the same time, the transient saturation zone is connected with the reservoir water level. The increase in pore water pressure caused by snow water infiltration. As a result, the effective stress at the toe of slope decreases, and the vertical displacement increases.

Figure 11(c) is "water hammer" mechanism reflected in bank slope deformation-failure under combined action of reservoir water and ice-snow melting. The reservoir water rapidly inundates the ice-snow covered by the landslide front edge. At this time, the ice and snow rupture expansion area is directly connected with the reservoir water with high water head. The reservoir water rapidly penetrates into icesnow mass. The flow of reservoir water produces cracks on the ice surface, and the negative pressure area is formed by the fracture opening. The rapid inflow of reservoir water had 
driven the ice blocks on both sides to close quickly. After, because the ice-snow was quickly soaked in the reservoir water, the crack outlet was blocked due to poor discharge. The phenomenon of "water hammer" can be produced at this time. A large amount of excess pore water pressure with high water head is caused on the sudden ice and snow fracture surface. The $10 \mathrm{~cm}$ fountain had been ejected from ice and snow cracks. The ice and snow covered on the slope moves towards the reservoir water. Its leading edge bears the buoyancy of reservoir water, causing ice and snow mass to "break." The reservoir water rapidly penetrates into the ice and snow cracks under the water head difference of $100 \mathrm{~cm}$. Because of the narrow crack at the outlet, blocking highspeed flow of water forms fountain. The mechanism of water hammer is of great significance to the sudden collapse of underwater rock and soil in front of the bank slope.

4.4. Update of Soil Particle Volume, Porosity, Saturation, and Permeability. For update, the geometry structure of the soil skeleton and the deformation gradient were updated within each time step using the following equation:

$$
I_{\mathrm{sp}}^{n+1}=\mathrm{d} I_{\mathrm{sp}}^{n+1} I_{\mathrm{sp}}^{n}
$$

where $\mathrm{d} I_{\mathrm{sp}}^{n+1}$ is the incremental deformation gradient given as

$$
\mathrm{d} I_{\mathrm{sp}}^{n+1}=I-\Delta t \sum_{i} G_{\mathrm{ip}}^{n} V_{\mathrm{si}}^{n},
$$

in which $G_{\mathrm{ip}}^{n}$ is the gradient function. The strain rates of both solid and liquid phases on particle $V_{\mathrm{si}}^{n}$ are calculated with the corresponding nodal velocities. The updated Jacobian of the transformation of the solid phase $J_{p}^{n+1}$ which is the determinant of the deformation gradient is as follows:

$$
J_{p}^{n+1}=\operatorname{det}\left(I_{\mathrm{sp}}^{n+1}\right),
$$

in which we determine the current volume and porosity:

$$
V_{p}^{n+1}=J_{p}^{n+1} V_{p}^{0}
$$

where $V_{p}^{0}$ is the initial particle volume prior to any deformation. It is usually expressed as a function of both suction $\left(p_{\mathrm{Lp}}^{n+1}\right)$ and porosity $\left(n_{p}^{n+1}\right)$ in case of large deformations, and $S_{\mathrm{Lp}}^{n+1}$ is the saturation.

$$
S_{\mathrm{Lp}}^{n+1}=f\left(p_{\mathrm{Lp}}^{n+1}, n_{p}^{n+1}\right) .
$$

The updated porosity and saturation were obtained, and the current permeability of each particle would be updated with constitutive law dependent on the porosity and saturation.

$$
k_{\mathrm{Lp}}^{n+1}=k_{L}^{0} k_{r}\left(S_{\mathrm{Lp}}^{n+1}, n_{p}^{n+1}\right),
$$

where $k_{L}^{0}$ is the initial soil hydraulic conductivity.

The erosion law, which is adopted to govern the internal erosion process in this research, is developed based on model test results, shown in Figures 11(a) and 11(b). In this simulation, the hydraulic gradients as same as the velocity fields are homogenous with the depth; therefore, homogenous erosion rates will be generated, which lead to homogenous fine content distributions within the soil specimens. The evaluation profiles of the eroded fines mass ratio in the specimens under different constant seepage velocities are presented in Figure 13.

As can be seen, consistent with the erosion model, the erosion rate increases with the applied hydraulic gradient (seepage velocity), and the fine particles inside soils will be eroded until the fine content fraction reaches the ultimate (long term) fine content fraction which is also dependent on the seepage velocity. The OPTUM-G2 simulation replicates the results as well as the experimental results quite well. Note that the discrepancy in the erodible mass between the numerical and the experimental results is due to the inaccuracies in the ultimate mass fraction curve. In our coupled OPTUM-G2 framework, the internal erosion effect is mainly accounted for the porosity change. In the model, two contributions for the porosity change can be identified, the skeleton deformation and the interphase mass transfer of fine species, which are difficult to be separated in the experiment. In this example, to validate the implementation of this seepage-erosion module, the skeleton deformation is assumed to be restricted. Accordingly, the porosity varies only with the internal erosion process. As shown in Figure 13, the porosity profiles simulated by the OPTUM-G2 almost overlap with the ones obtained by test values, which are proportional to the erosion process.

\section{Deformation Failure Mechanism}

5.1. Quantitative Analysis of Creep Damage. The creep displacement of landslide is essentially the damage and deformation evolution of rock and soil. Creep type slope refers to that under the action of gravity, and the sliding deformation soil mass has obvious creep characteristics; that is, deformation has the characteristics of slow evolution with time. This kind of slope is a dynamic development process from stable deformation to instability failure. The stress and strain develop continuously with time, and the deformation development lasts for long time. The larger creep deformation occurs before the instability. The displacement changes the physical mechanical properties and slip boundary conditions.

There are three stages from initial displacement to slope failure. There are initial creep stage, isokinetic creep stage, and accelerated creep stage. Different deformation stages have different deformation evolution characteristics and damage mechanism. The evolution of landslide is essentially the process of damage and deformation. The model test is carried out on creep slope with constant gravity field. Slope creep displacement and creep law decide the damage variable of bank slope. We quantitatively analyzed the slope displacement and slope damage variables. We established the quantitative relationship between damage variable and creep displacement of slope.

The creep displacement of slope is produced under icesnow melting influent load. The slope material is weakened 


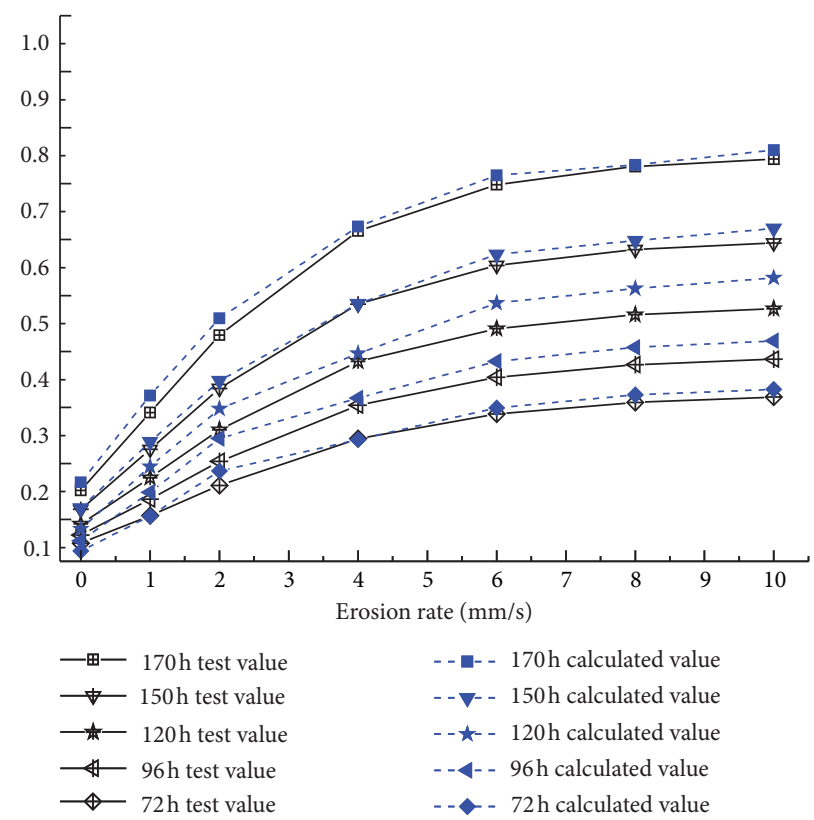

FIgURE 13: Variations of hydraulic gradient and time with average internal erosion velocity.

due to water seepage erosion and time creep effect, resulting in irreversible creep and plastic deformation.

In this study, the hydraulic gradient changes from 0.53 to 0.66 , which is greater than critical hydraulic gradient, and internal erosion will occur in landslide. The corresponding internal erosion control equation is the relationship between the porosity of soil mass, the mass of eroded particles, and the loss rate of fine particles.

Internal erosion under combined action of reservoir water and ice-snow melting occurs, and the fine particles are separated from the soil skeleton. In this hypothesis, the velocity of movement is consistent with the water flow. Cividini [40] proposed that the continuity equation of internal erosion is obtained by the law of conservation of mass:

$$
\frac{\partial \rho_{t}}{\partial t}+\frac{\partial\left(\rho_{t} v_{i}\right)}{\partial x_{i}}=q_{e}-q_{d},
$$

where $\rho_{t}$ is the density of eroded fine particles; $v_{i}$ is the moving speed of eroded particles in I direction; $q_{e}$ is the rate of erosion per unit volume of fine particles; and $q_{d}$ is the rate of deposition of eroded particles into the soil skeleton.

When fine particles are eroded, fine particles flow with water. Density of eroded soil particles $\rho$ fs is as follows:

$$
\bar{\rho}_{\mathrm{fs}}=c \varphi \rho_{s},
$$

which were calculated from equations 10 and 9; continuity governing equation of internal erosion is as follows:

$$
\frac{\partial \bar{\rho}_{\mathrm{fs}}}{\partial t}+\frac{\partial\left(\bar{\rho}_{\mathrm{fs}} v_{i}\right)}{\partial x_{i}}=q_{e}-q_{d} .
$$

The seepage state in soil is very complex, and Darcy flow, non-Darcy flow, and dominant flow can exist at the same time. Equations describing the seepage state of soil are also different. But, in the early stage of internal erosion, Darcy flow is the main seepage in soil.

Based on the Carman-Kozeny equation, the relationship between saturation permeability coefficient $K_{\mathrm{s}}$ and porosity $n_{0}$ is as follows:

$$
K_{s}=\frac{n^{3}}{(1-n)^{2}} \frac{\left(1-n_{0}\right)^{2}}{n_{0}^{3}} K_{s 0},
$$

where $n_{0}$ is the initial porosity; ks0 is the initial saturated permeability coefficient; and $n$ is the porosity of soil after snow water infiltration. Ice-snow melting intensity is closely related to the deformation and failure mode of landslide.

5.2. The Deformation Mechanism of Bank Slope. Based on the above analysis, the bank slope deformation analysis model under the combined action of ice-snow melt water and reservoir water is built. In addition, the deformation and failure mechanism of bank slope under the combined action of icesnow melt water and reservoir water are thus expounded.

(1) Under the condition of ice-snow melting, the existence of cracks enhanced the infiltration capacity and the infiltration path of the slope soil. The snow water infiltrated from the fissure to both sides and the surface of the slope. The fissure layer was then saturated, and the stability was obviously reduced, as shown in Step 1 of Figure 12.

(2) With the increase in crack depth of slope surface soil, the vertical range of the saturated area was directly affected. The width of the crack opening mainly affected the boundary size of the ice-snow melt water. The deeper the crack was, the larger the saturated area was and the lower the slope stability was, as shown in Step 2 of Figure 12. 


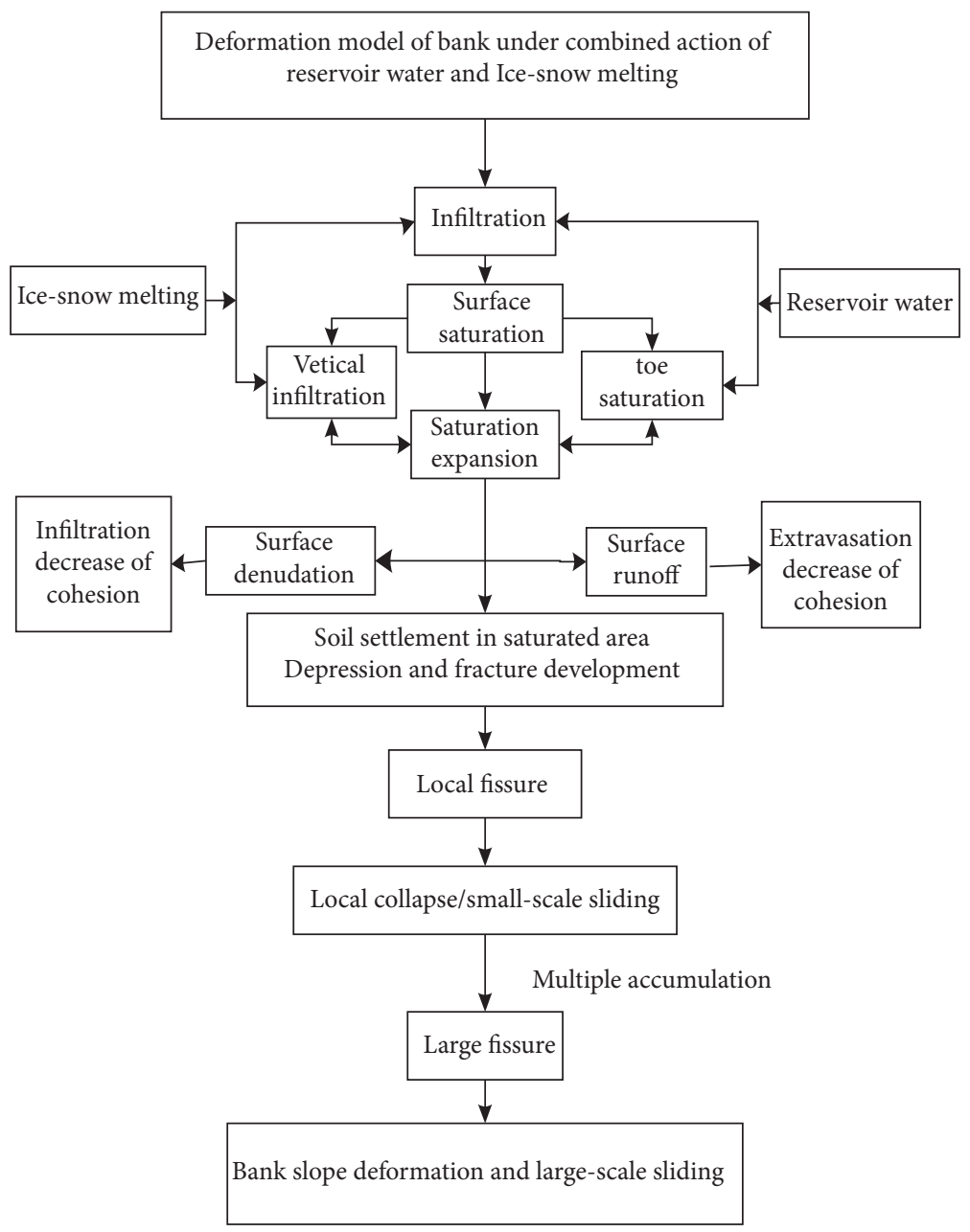

FIgURE 14: The deformation analysis model of bank slope.

(3) The distribution of the cracks would affect not only the stability of the slope but also the condition of the sliding surface. The cracks were distributed in the middle and front parts of the slope. Ice-snow melt water was easy to cause shallow damage and had a great influence on the stability of the slope where cracks are distributed, as shown in Step 3 of Figure 12.

(4) The speed of ice-snow melting mainly affected the saturation speed of the fracture soil on the surface. The saturation area of fracture layer increases with the extension of ice-snow water holding time, while the slope stability decreased with the increase in icesnow water melting strength. Finally, erosion and sliding deformation of the bank slope surface occurred, as shown in Step 4 of Figure 12.

During the day, the speed of ice and snow melting is faster than that at night. When the temperature is below $0^{\circ} \mathrm{C}$, the icesnow will not melt. The snow melting speed changes with the temperature during the whole day. The degradation of soil medium mechanics and seepage characteristics caused by ice and snow melting and freeze-thaw will inevitably cause the expansion of infiltration depth and saturation range of ice and snow melting water, especially the irreversible damage. At the peak of ice-snow melting water, the saturation range of icesnow melting water will be further expanded; the seepage pressure will be increased; the groundwater level will be raised; and the deformation damage will be intensified. As a whole, there is no obvious deformation and failure of the slope except for small denudation and collapse in the saturated area, as shown in Figure 14.

\section{Discussion}

In this paper, the soil material are assigned with the same material parameters, including the ones for Mohr-Coulomb model, Darcy seepage flow, internal erosion law, and soil water retention curve.

An erosion law is necessary to describe the phase transfer rate of solid fine particles to liquidize fine particles. Most of them are empirical relations which relate the erosion rate to the flow characteristics (velocity and hydraulic gradient), porosity, fines density, and empirical erosion coefficients. In this study, the variation of fine particles content in the soil skeleton is assumed to be due only to the suffusion. The erosion law [41] is chosen to calculate the fines variation rate at pore surfaces. 


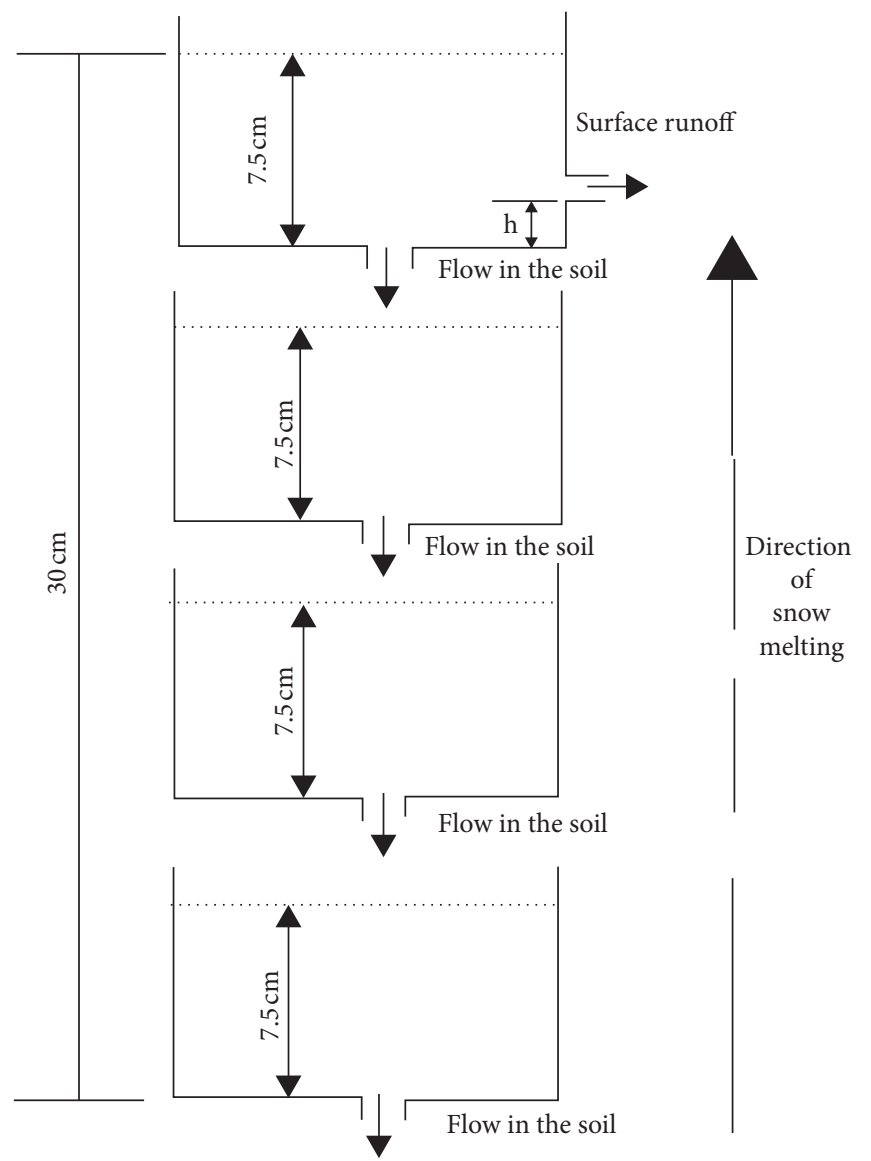

FIgURE 15: The tank model.

The surface soil temperature is higher than that of indoor air temperature. The process of ice-snow melting is from the bottom to the top of the contact layer between ice and soil. In this paper, the complex ice-snow melting runoff process is conceptualized as the water tank connection relationship of water storage outflows from bottom to top. With the storage depth and the outflow of the side hole and the outflow of the bottom hole [42], calculate the runoff, concentration, and infiltration. The temporal and spatial distribution of icesnow melting is complex. The water tanks in series are arranged, with simulation of runoff process of ice-snow melting [43]. The theoretical diagram of water tank infiltration is as shown in Figure 15.

The landslide soil is supposed to be a homogenous clay soil, whose fine particles can be eroded upon snow-ice melting infiltration. The Mohr-Coulomb model using Bishop's effective stress [44, 45] presented is adopted to capture the soil failure behavior, and the V-G equation is adopted as the soil water retention law:

$$
S_{L}=S_{\min }+\left(1-S_{\min }\right)\left[1+\left(b_{v} \frac{S_{c}}{S_{\text {ref }}}\right)^{m_{v}}\right]^{-\left(1-\left(1 / m_{v}\right)\right)},
$$

in which $S_{L}$ is the liquid saturation; $S_{\mathrm{c}}$ and $S_{\text {ref }}$ are the matric suction and the reference suction values; $S_{\min }$ is the minimum (residual) saturation can be reached; and $b_{\mathrm{v}}$ and $m_{\mathrm{v}}$ are fitting parameters.

The impact of the variation of porosity on the intrinsic permeability relies on the liquid permeability on the level of saturation [46, 47], as in the following power law:

$$
k_{r}\left(m, S_{L}\right)=\left(\frac{m}{m_{0}}\right)^{3} S_{L}^{3}
$$

\section{Conclusions}

This paper is based on the three-dimensional landslide test platform. According to the landslide prototype and the similarity theory, a large-scale physical model test was constructed. The deformation characteristics and influence mechanism of landslide are studied under the action of reservoir water level rise, ice-snow melting, and their combination. The conclusion is as follows:

(1) In the early stage of water level rise, the effective stress increases the formation of seepage pressure in the slope. When the landslide mass is deformed and damaged, the response of pore water pressure and earth pressure of shallow soil is obvious, and when 
the deformation and failure of landslide occur, the sensor response lags in slope.

(2) Directly affected by reservoir water, the soil at the front edge of the bank slope is saturated rapidly under the action of ice-snow melt water, the shear strength is greatly reduced, with deterioration of stability. After, the edge is steeper due to continuous infiltration of snow-ice melting, the glide force increases and the downward penetration force is larger. During snowmelt infiltration, with the increase in pore water pressure, the shear strength gradually decreases; on the upper side of the failure zone, tensile cracks will occur; the lower side of the soil swells due to the extrusion, and local flowing soil will occur at the foot of slope.

(3) In this model test, the infiltration of ice and snowmelting is the key factor to induce the deformation and instability of accumulation landslide. The icesnow melting intensity will increase the pore water pressure and the earth pressure. In the accelerated deformation stage, pore water pressure and soil pressure are fluctuated abnormally frequently. It is the sign of slope instability, which provides a certain reference for landslide early warning and prediction.

(4) The formation of tensile cracks is the most fundamental reason to accelerate the creep deformation and failure of accumulation landslide. After 3 days of joint action, the surface soil has shallow erosion deformation. After 4 days of ice and snow melting, obvious thorough creep sliding deformation and failure occurred in the left part of the front edge of the bank slope. After 5 days of combined action, it is affected by the disturbance caused by the rate of ice and snow melting alternately day and night. There are large transverse cracks in the front and middle parts of the slope; under the transverse cracks, there are some areas of thorough dislocation failure area. During a period of time after the end of ice-snow melting on the surface of the bank slope, under the joint action of reservoir water, the pressure head of local slope did not obviously decrease. It may continue to increase due to the influence of reverse osmosis and dynamic water cycle effect, and creep deformation occurs on the bank slope.

(5) The response law of pore water pressure and earth pressure and the deformation and failure mode of slope with different profiles, depths, and snowmelt intensities are studied. The response time of pore water pressure and soil pressure to snow melting intensity is positively proportional to the snow melting intensity.

\section{Data Availability}

The test data are included within the article and are available from the corresponding author upon request.

\section{Conflicts of Interest}

The authors declare that they have no conflicts of interest regarding the publication of this paper.

\section{Acknowledgments}

This work was supported in part by the National Natural Science Foundation of China (NSFC) (grant nos. 51809151, 51439003, 51979218, and U1965107), in part by the Program for China Three Gorges University Excellent Research Dissertation (grant no. 2018BSPY004), and by the Natural Science Foundation of Hubei Province (grant no. Z2018063) and Natural Science Foundation of Shanxi Province (grant no. 2018JM5118).

\section{References}

[1] J. A. Wang, J. X. Zhou, and F. Li, "Studies on the space-time evolution rule and cladding tube mechanical response," Rock and Soil Mechanics, vol. 41, no. 1, pp. 1-13, 2020.

[2] J. Wang, W. Xiang, and N. Lu, "Landsliding triggered by reservoir operation: a general conceptual model with a case study at Three Gorges Reservoir," Acta Geotechnica, vol. 9, no. 5, pp. 771-788, 2014.

[3] L. Peng and R. Q. Niu, "Analysis on deformation characteristics and influential factors of Baijiabao landslide in the Three Gorges Reservoir area," Chinese Journal of Geological Hazard \& Control, vol. 22, pp. 1-7, 2011.

[4] S. Lu, G. Zhang, Q. Yi, W. Yi, and H. Huang, "Characteristics and mechanism of dynamic deformation of Baijiabao landslide with stepwise in Three Gorges Reservoir Area," SouthTo-North Water Transfers and Water Science \& Technology, vol. 14, no. 3, pp. 144-149, 2016.

[5] N. Zhao, B. Hu, Q. Yi, W. Yao, and C. Ma, "The coupling effect of rainfall and reservoir water level decline on the Baijiabao landslide in the Three Gorges Reservoir Area, China," Geofluids, vol. 2017, Article ID 3724867, 12 pages, 2017.

[6] W. Jian, Q. Xu, H. Yang, and F. Wang, "Mechanism and failure process of Qianjiangping landslide in the Three Gorges Reservoir, China," Environmental Earth Sciences, vol. 72, no. 8, pp. 2999-3013, 2014.

[7] J.-W. Jiang, W. Xiang, J. Rohn, W. Zeng, and M. Schleier, "Research on water-rock (soil) interaction by dynamic tracing method for Huangtupo landslide, Three Gorges Reservoir, PR China," Environmental Earth Sciences, vol. 74, no. 1, pp. 557-571, 2015.

[8] S. Sellers, "Theory of water transport in melting snow with a moving surface," Cold Regions Science and Technology, vol. 31, no. 1, pp. 47-57, 2000.

[9] Y. X. Zhang, X. C. Song, and G. L. Wang, "Analysis of rock slope overturning stability under extreme ice and snow conditions," Journal of Rock Mechanics and Engineering, vol. 29, no. 6, pp. 1164-1171, 2010.

[10] X. H. Qian, G. Rong, and K. Huang, "Seepage calculation and stability analysis of slope under melting snow infiltration," Chinese Journal of Geological Hazards and Prevention, vol. 21, no. 4, pp. 27-33, 2010.

[11] Q. Xu, Z. H. Liu, and S. F. Fang, "Retrieval method for estimating snow depth using hyperspectral data in snowmelt 
period," Spectroscopy and Spectral Analysis, vol. 33, no. 7, pp. 1927-1931, 2013.

[12] Q. Ge, Study on Soil Slope Stability in Seasonal Frozen Area Based on Strength Damage of Freezing-Thawing Interface, Jilin University, Changchun, China, 2010.

[13] X. D. Huang, X. T. Zhang, and X. Li, "Accuracy analysis for MODIS snow products of MODIOA1and MOD10A2 in northern Xinjang Area," Journal of Glaciology and GeocryOlogy, vol. 29, no. 5, pp. 722-729, 2007, in Chinese.

[14] T. G. Gao, Analysis and Simulation of the Hydrological Processes in the Nam Co Basin,Tibet an Plateau, Chinese Academy of Sciences, Bei jing, China, 2011, in Chinese.

[15] Y. Cao, K. Yin, D. E. Alexander, and C. Zhou, "Using an extreme learning machine to predict the displacement of steplike landslides in relation to controlling factors," Landslides, vol. 13, no. 4, pp. 725-736, 2015.

[16] G. M. Xu, Study on Mechanical Properties of Low-Temperature, Freeze-Thaw Damage and Multi-Field Coupling of Rock Mass in Cold Zone, Graduate School of Chinese Academy of Sciences (Wuhan Institute of Geotechnical Mechanics), Wuhan, China, 2006.

[17] M. S. Cao, X. Li, and X. Z. Chen, Remote Sensing of Cryosphere, Science Press, Beijing, China, 2006pp. 119-123, (in Chinese).

[18] G. S. Zhang, A Study of Zhadang Glacier Energy and Mass Balance and Its Hydrological Processes in $\mathrm{Na} \mathrm{M}$ Co Basin Central Tibetan Plateau, Chinese Academy of Sciences, Beijing, China, 2013, (in Chinese).

[19] Z. M. Guo and N. L. Wang, "Progress in the research on snow grain size retrieved from remote Sensing," Journal of Glaciology and Geocryology, vol. 33, no. 3, pp. 539-545, 2011.

[20] F. Chen, Q. G. Cai, M. G. Zheng, and L. Y. Sun, "Melting characteristics and ablation calculation in Nam Co basin," Journal of Mountain Research, vol. 33, no. 4, pp. 465-472, 2015, in Chinese.

[21] L. S. Xiong, C. J. Lin, and J. RXu, "Application of energy balance snowmelt model on sunny slope in western Tianshan Mountains," Agricultural Science and Technology, vol. 13, no. 4, pp. 872-876, 2012.

[22] H. M. Zhang and G. S. Yang, "Freeze-thaw cycling and mechanical experiment and damage propagation characteristics of rock," Journal of China University of Mining \& Technology, vol. 40, no. 1, pp. 140-146, 2011.

[23] T. F. Wei, Z. H. Liu, and Y. Wang, "Effect of seasonal frozen soil under snow cover on outflow of snowmelt water," Arid Zone Research, vol. 32, no. 3, pp. 435-441, 2015.

[24] L. N. Guo, "Research progress on limit state of slope under extreme snow and ice," Water Conservancy and Hydropower Technology, vol. 50, no. 2, pp. 191-201, 2019.

[25] Y. Q. Yu, Research on Freezing-Thawing Damage of ShortTime Frozen Soil and Shallow Slope Stability, Fuzhou University, Fuzhou, China, 2015.

[26] H. Liu, F. J. Niu, and Z. Y. Xu, “Acoustic experimental study of two types of rock from the Tibetan Plateau under the condition of freeze-thaw cycles," Sciences in Cold and Arid Regions, vol. 4, no. 1, pp. 21-27, 2012.

[27] W. Xiang and X. Liu, "Experimental study on mechanical properties of rock shotcrete composite specimens under freeze-thaw cycles," Journal of Rock Mechanics and Engineering, vol. 29, no. 12, pp. 2510-2521, 2010.

[28] A. Vallet, J. B. Charlier, O. Fabbri, C. Bertrand, N. Carry, and J. Mudry, "Functioning and precipitation-displacement modelling of rainfall-induced deep-seated landslides subject to creep deformation," Landslides, vol. 13, no. 4, pp. 653-670, 2015.
[29] S. R. Xiao, D. F. Liu, and F. X. Jiang, "Geomechanical model experiment on Qianjiangping landslide in three gorges reservoir area," Chinese Journal of Rock Mechanics and Engineering, vol. 29, no. 5, pp. 1023-1030, 2010.

[30] J. Zhao, W. U. Jian, and H. Yan, "Model test study on deformation mechanism of baijiabao landslide," Water Resources \& Power, 2012.

[31] Z. Li, Y. J. HE, H. E. Li, and H. F. Xu, "Model test on slope landslides under antecedent rainfall," Journal of Hohai University (Natural Sciences), vol. 44, no. 5, pp. 400-405, 2016.

[32] X. Q. Luo, D. F. Liu, J. Wu et al., "Model test study on landslide under rainfall and reservoir water fluctuation," Chinese Journal of Rock Mechanics and Engineering, vol. 24, no. 14, pp. 2476-2483, 2005.

[33] Q. H. Zhan, S. M. Wang, and D. P. Zhao, "Model test study on landslide with weak layers under up rise of reservoir water," Journal of Yangtze River Scientific Research Institute, vol. 33, no. 2, pp. 86-90, 2016.

[34] S. J. Li, Q. C. Sun, and Z. H. Zhang, "Physical modelling and numerical analysis of slope instability subjected to reservoir impoundment of the Three Gorges," Environmental Earth Sciences, vol. 77, no. 4, pp. 138.1-138.17, 2018.

[35] Y. J. Zhang, E. Z. Wang, and S. J. Wang, "Fluid-solid coupling in unsaturated soils," Rock and Soil Mechanics, vol. 25, no. 6, pp. 999-1004, 2004, in Chinese.

[36] Z. P. Li and M. Zhang, "Study on transient safety coefficient of unsaturated soil slope considering rainfall infiltration," Journal of Civil Engineering, vol. 34, no. 5, pp. 57-61, 2001.

[37] X. Q. Luo, S. G. Cheng, and E. K. Niu, "Study on distortion correction and application of landslide physical model test," Journal of Rock Mechanics and Engineering, vol. 28, no. S1, pp. 3082-3088, 2009.

[38] D. Sterpi, "Effects of the erosion and transport of fine particles due to seepage flow," International Journal of Geomechanics, vol. 3, no. 1, p. 111, 2003.

[39] X. Q. Lei, S. M. He, and X. Q. Chen, “A generalized interpolation material point method for modelling coupled seepage-erosion-deformation process within unsaturated soil," Advances in Water Resources, vol. 141, pp. 1-19, 2020.

[40] L. Q. Mou, "Study on thermodynamic watershed hydrological model for cold regions," Ph. D Thesis, Tsinghua University, Beijing, China, 2008.

[41] A. Cividini and G. Gioda, "Finite-element approach to the erosion and transport of fine particles in granular soils," International Journal of Geomechanics, vol. 4, no. 3, pp. 191-198, 2004.

[42] X.-Q. Lei, Z.-J. Yang, S.-M. He, E.-L. Liu, H. Wong, and X.-P. Li, "Hydro-mechanical analysis of rainfall-induced fines migration process within unsaturated soils," Journal of Mountain Science, vol. 14, no. 12, pp. 2603-2619, 2017.

[43] R. B. Wang and W. Y. Xu, "Study on physical simulation of rainfall infiltration process of landslide accumulation body," Advanced Engineering Sciences, vol. 51, no. 4, pp. 47-54, 2019.

[44] R. Uzuoka, T. Ichiyama, T. Mori, and M. Kazama, "Hydro mechanical analysis of internal erosion with mass exchange between solid and water," in Proceedings of the 6th International Conference on Scour and Eros-ion, pp. 655-662, Paris, France, August 2012.

[45] L. Zhang, F. Wu, H. Zhang, L. Zhang, and J. Zhang, "Influences of internal erosion on infiltration and slope stability," Bulletin of Engineering Geology and the Environment, vol. 78, no. 3, pp. 1-13, 2019.

[46] B. Yuan, L. Xiong, L. Zhai et al., "Transparent synthetic soil and its application in modeling of soil-structure interaction 
using optical system," Frontiers in Earth Science, vol. 7, p. 276, 2019.

[47] B. X. Yuan, M. Sun, Y. X. Wang, L. H. Zhai, and Q. Z. Luo, "Full 3D displacement measuring system for 3D displacement field of soil around a laterally loaded pile in transparent soil," International Journal of Geomechanics, vol. 19, no. 5, Article ID 04019028, 2019. 